\title{
CORRELATION BETWEEN PREGNANCY HYPERTENSION TYPES FROM THE POINT OF VIEW OF PLACENTAL VASCULARIZATION INDICES MEASURED BY 3-DIMENSIONAL POWER DOPPLER
}

\author{
Ph.D. Thesis \\ Ábel Tamás, Altorjay, M.D. \\ University of Szeged \\ Albert Szent-Györgyi Health Centre \\ Faculty of Medicine \\ Department of Obstetrics and Gynecology
}

\author{
Supervisors: \\ Gábor Németh, M.D., Ph.D., Med. Habil. \\ University of Szeged \\ Albert Szent-Györgyi Health Centre \\ Faculty of Medicine \\ Head of Department of Obstetrics and Gynecology \\ Andrea Surányi, M.D., Ph.D., Med. Habil. \\ University of Szeged \\ Albert Szent-Györgyi Health Centre \\ Faculty of Medicine \\ Department of Obstetrics and Gynecology
}

\section{Director of Doctoral School of Clinical Medicine: \\ Lajos Kemény, M.D., D.Sc. \\ Director of Reproductive Health Programme: \\ György Bártfai, M.D., D.Sc.}

\author{
University of Szeged \\ Albert Szent-Györgyi Health Centre \\ Faculty of Medicine \\ Department of Obstetrics and Gynecology
}

Szeged, 2017. 


\section{List of publications}

I. Suranyi $\mathrm{A}^{1}$, Altorjay $\mathbf{A T}^{1}$, Kaiser L, Nyari T, Nemeth G. Evaluation of placental vascularization by three-dimensional ultrasound examination in second and third trimester of pregnancies complicated by chronic hypertension, gestational hypertension or pre-eclampsia. Preg Hypertens. 2017;8:51-9. IF 2016: 3,930

${ }^{1}$ These authors contributed equally.

II. Altorjay AT, Suranyi A, Nyari T, Nemeth G. Use of placental vascularization indices and uterine artery peak systolic velocity in early detection of pregnancies complicated by gestational diabetes, chronic or gestational hypertension, and preeclampsia at risk. Croat Med J. 2017;58:161-9. IF2016: 1,570

\section{Other publications}

I. Balint A, Berenyi A, Farkas K, Pallagi-Kunstar E, Altorjay AT, Csonka A, Krizsan M, Szucs M, Pal A, Fabian A, Bor R, Milassin A, Szulcsan A, Rutka M, Szepes Z, Molnar T. Pregnancy does not affect fecal calprotectin concentration in healthy women. Turk J Gastroenterol. 2017;28:171-5. IF2016: 0,932

\section{Citable abstracts}

I. Altorjay AT, Suranyi A, Jako M, Kaiser L, Nyari T, Nemeth G. Correlation between placental vascularization indices and histological findings of placentas in pregnancy hypertension. ULTRASOUND IN OBSTETRICS AND GYNECOLOGY 2017;50(S1):166 IF 2016: 4,710

II. Altorjay AT, Suranyi A, Vulin M, Muller A, Nemeth G. Correlation between placental vascularization indices and sFlt/PlGF ratio, in preeclampsia screening: study progress. UKRAINIAN BIOCHEMICAL JOURNAL 2017;89:77.

III. Altorjay AT, Suranyi A, Nyari T, Nemeth G. Pregnancy hypertension, gestational diabetes mellitus and pre-eclampsia from the point of view of uterine artery peak systolic velocity and placental vascularization indices - a preliminary study. EUROPEAN JOURNAL OF OBSTETRICS GYNECOLOGY AND REPRODUCTIVE BIOLOGY 2016;206:127. IF 2016: 1,666

IV. Suranyi A, Altorjay AT, Nyari T, Jako M, Nemeth G. EP17.13: Fetal renal vascularisation effected by gestational hypertension. ULTRASOUND IN OBSTETRICS AND GYNECOLOGY 2016;48:(Suppl 1)342. IF2016: 4,710 
V. AT Altorjay, A Suranyi, M Jako, T Nyari, G Nemeth, A Pal. Effect of pregnancies complicated by essential as well as pregnancy induced hypertension on placental vascularization. PREGNANCY HYPERTENSION 2015;5:33. IF 2015: 1,308

VI. Altorjay AT, Suranyi A, Nyari T, Nemeth G. Placental vascularization indices and uterine artery peak systolic velocity in pregnancy hypertension. PREGNANCY HYPERTENSION 2015;5:240. IF 2015: 1,308

VII. Altorjay AT, Suranyi A, Nyari T, Jako M, Nemeth G. Placental vascularization indices and uterine artery peak systolic velocity in pregnancies complicated with hypertension and gestional diabetes. ULTRASOUND IN OBSTETRICS AND GYNECOLOGY 2015;46:200. IF 2015: 4,197

VIII. Suranyi A, Altorjay AT, Nemeth G. Fetal renal vascularization in pregnancy induced hypertension complicated by gestational diabetes or intrauterine growth restriction. PREGNANCY HYPERTENSION 2015;5:241-2. IF 2015: 1,308

IX. Suranyi A, Altorjay AT, Nyari T, Pal A. Evaluation of fetal renal vascularization in pregnancies complicated by essential and pregnancy induced hypertension. PREGNANCY HYPERTENSION 2015;5:9-10. IF 2015: 1,308

X. Altorjay AT, Suranyi A, Molnar A, Jako M, Nyari T, Pal A. Examination of placental vascularisation with 3-dimensional ultrasound technology in pregnant women with hypertension. ULTRASOUND IN OBSTETRICS AND GYNECOLOGY 2014;44:262. IF 2014: $\mathbf{3 , 8 5 3}$

XI. Altorjay AT, Suranyi A, Molnar A, Nyari T, Pal A. A placenta vaszkularizációjának vizsgálata 3-dimenziós ultrahang technikával magas vérnyomással szövődött terhességekben: Ultrahang. MAGYAR NÖORVOSOK LAPJA. 2014;77:175. 


\section{Table of contents}

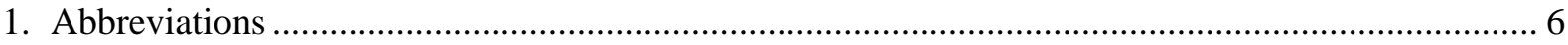

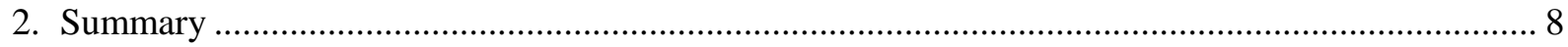

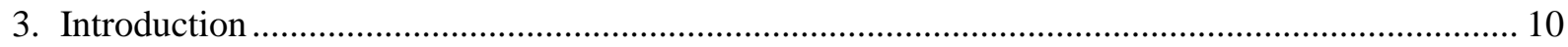

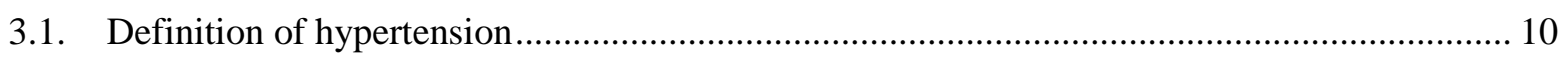

3.2. Classification of hypertensive disorders during pregnancy .......................................... 10

3.3. Hemodynamic changes in normal and preeclamptic pregnancy ...................................... 11

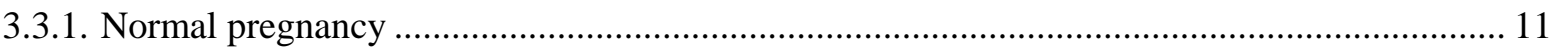

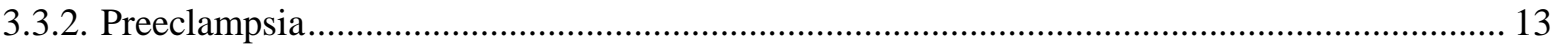

3.4. The Renin-Angiotensin Aldosterone System in normal pregnancy and preeclampsia............ 13

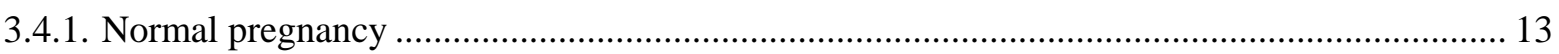

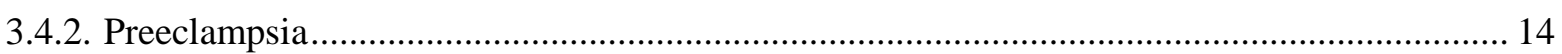

3.5. Platelets in normal pregnancy and preeclampsia..................................................... 14

3.6. Coagulation in normal pregnancy and preeclampsia............................................. 14

3.7. The placentation process in normal pregnancy and pregnancy hypertension ...................... 15

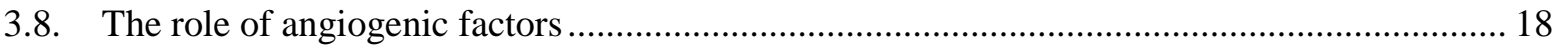

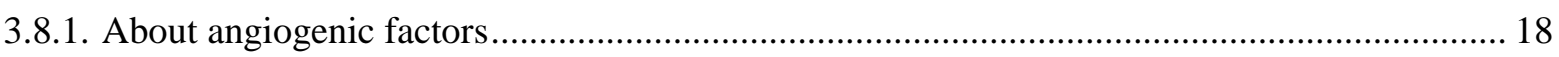

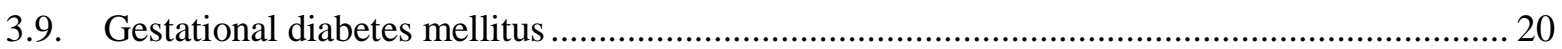

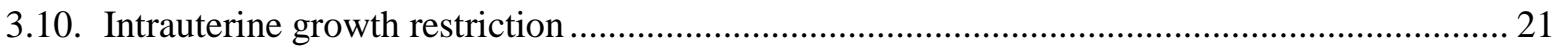

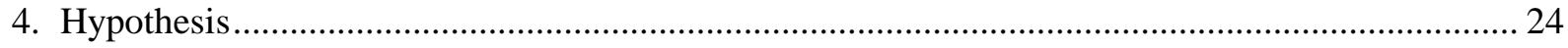

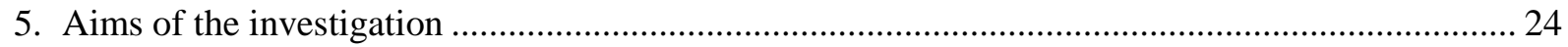

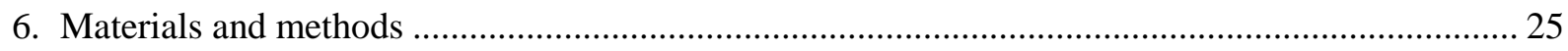

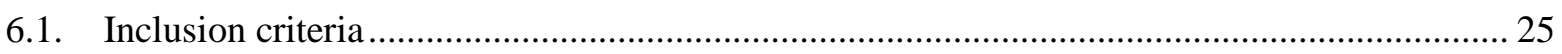

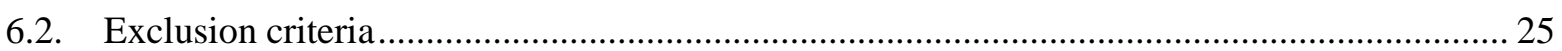

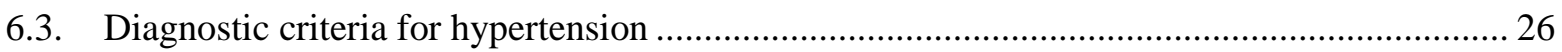

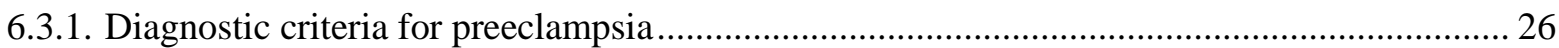

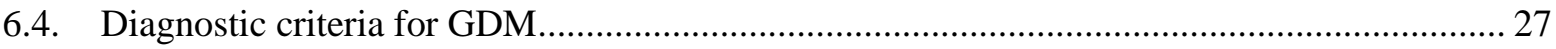

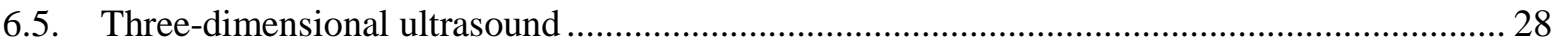

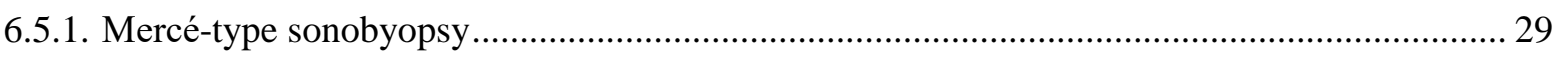

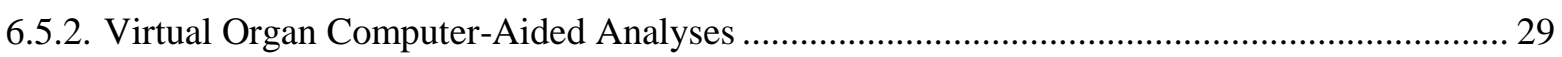

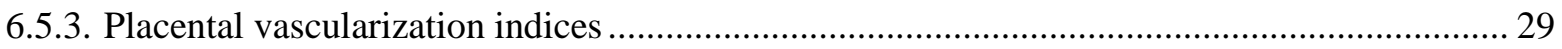

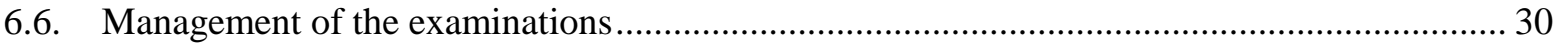

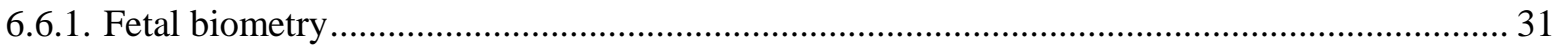

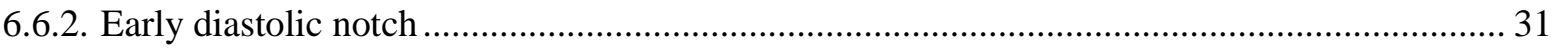

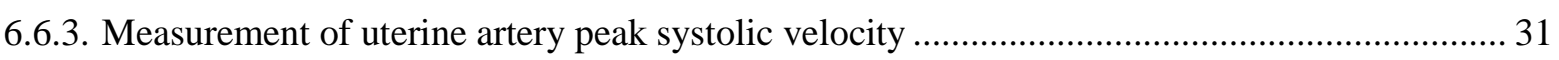

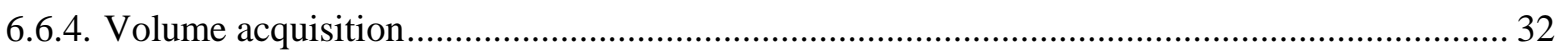

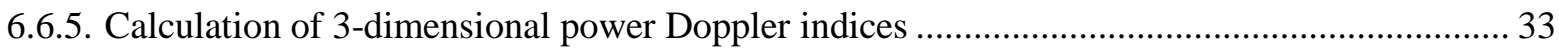




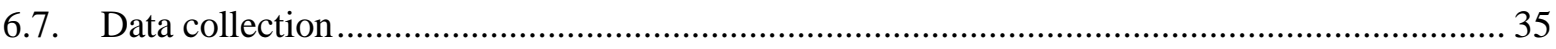

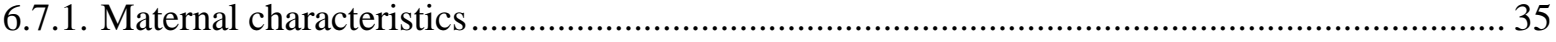

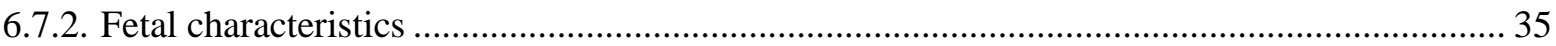

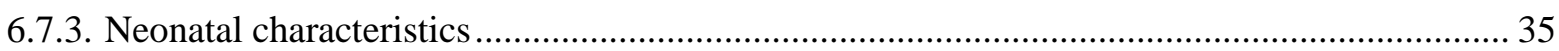

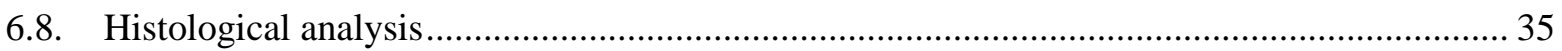

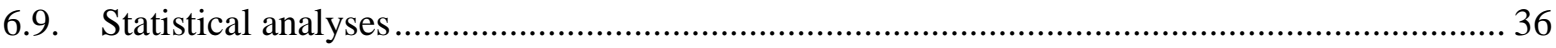

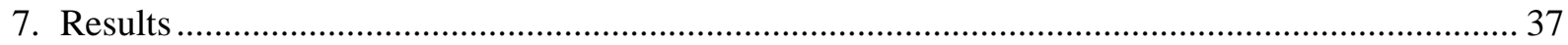

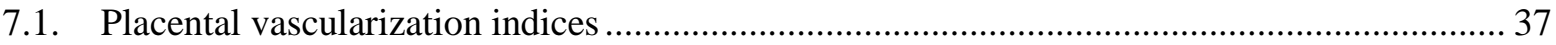

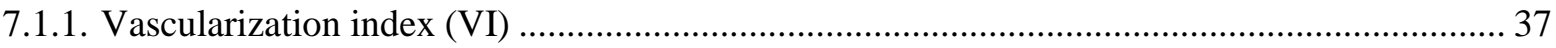

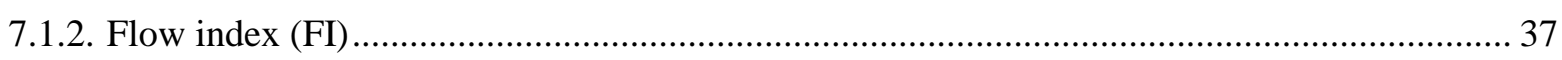

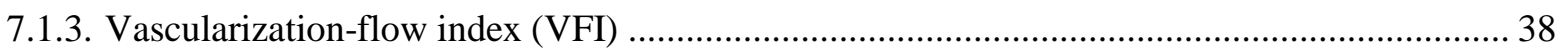

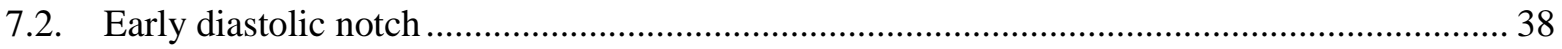

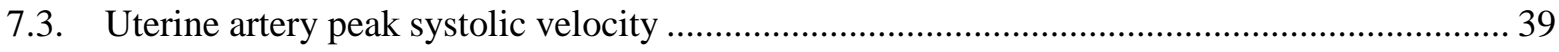

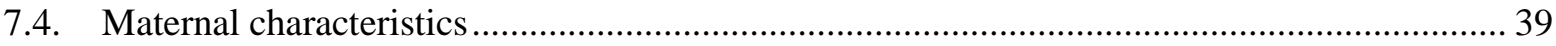

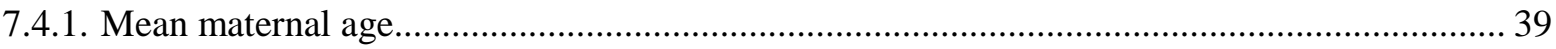

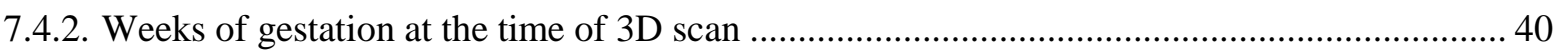

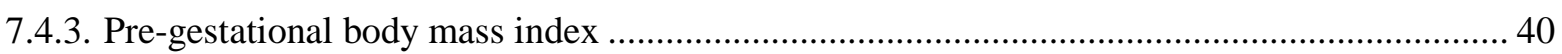

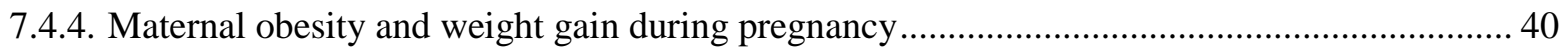

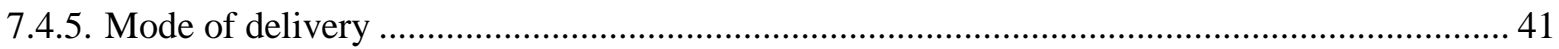

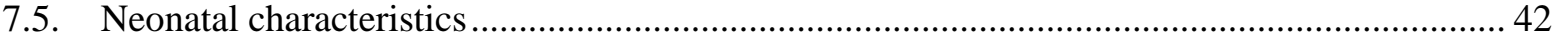

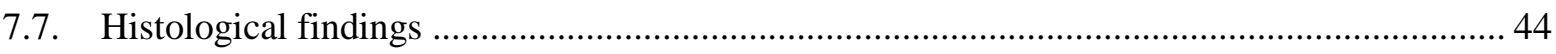

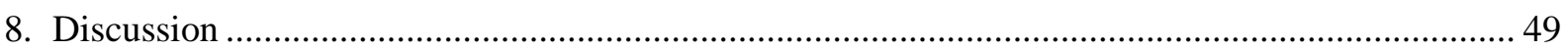

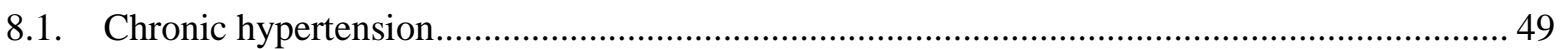

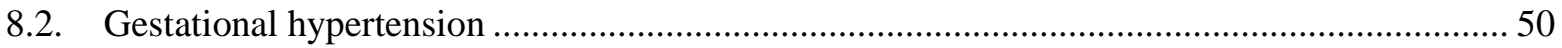

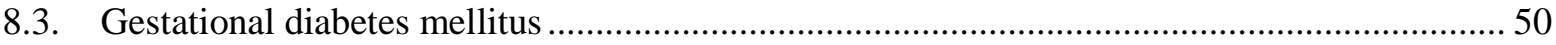

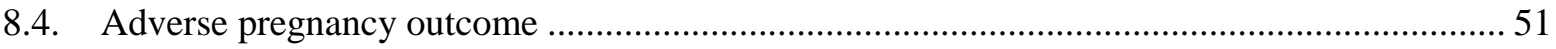

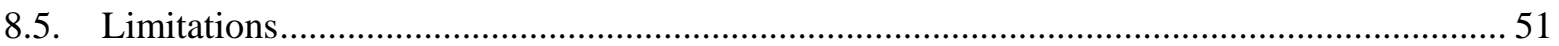

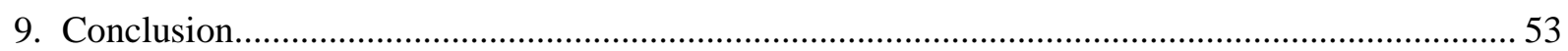

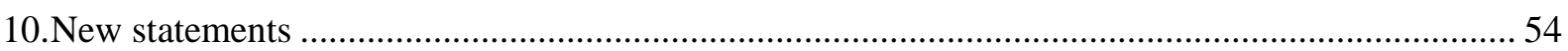

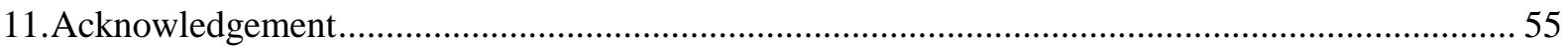

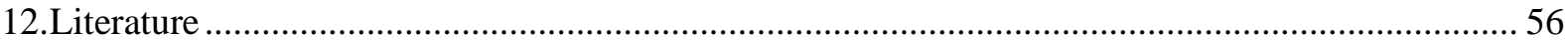

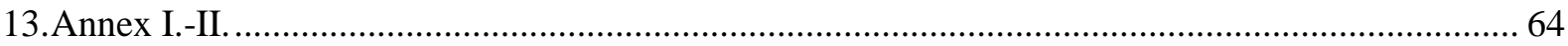




\section{Abbreviations}

2-D two-dimensional

3-D three-dimensional

3-DPD three-dimensional power Doppler

AC abdominal circumference

ACOG American College of Obstetrics and Gynecology

ADP adenosine diphosphate

AUtPSV uterine artery peak systolic velocity

BMI body mass index $(\mathrm{kg} / \mathrm{m} 2)$

BPD biparietal diameter

CHT chronic hypertension

CRL crown rump length

EFW estimated fetal weight

FI flow index

FL femur length

Flt-1 fms-like tyrosine kinase 1

Flk-1 fetal liver kinase 1

Flt-4 fms-like tyrosine kinase 4

GA gestational age

GDM gestational diabetes mellitus

GHT gestational hypertension

HC head circumference

HELLP hypertension, elevated liver enzymes, low platelets

ISSHP International Society for the Study of Hypertension during Pregnancy

IUGR intrauterine growth restriction

LGA large for gestational age

MAP mean arterial pressure

NBP normal blood pressure

NICE National Institute for Care and Excellence

NO nitrogen monoxide

OGTT oral glucose tolerance test

PD power Doppler

PE preeclampsia 
PI pulsatility index

PIGF placental growth factor

RCOG Royal College of Obstetricians and Gynecologists

RDS respiratory distress syndrome

RI resistance index

sFlt-1 soluble fms-like tyrosine kinase

SOGC Canadian College of Obstetricians and Gynecologists

TAF tumor angiogenic factor

UAPI uterine artery pulsatility index

VEGF vascular endothelial growth factor

VOCAL virtual organ computer-aided analysis

VPF vascular permeability factor

VFI vascularisation flow index

VI vascularisation index (\%)

WHO World Health Organization 


\section{Summary}

A prospective study was carried out to compare the rate of placental vascularization and the value of uterine artery peak systolic velocity (AUtPSV) between pregnancy hypertension types, and normal controls. Three-dimensional power Doppler (3-DPD) technique with Virtual Organ Computer-aided Analysis (VOCAL) software were used for the measurements in second and third trimester pregnancies.

In the evaluation of placentas, conventional two-dimensional (2-D) ultrasound has been world-wide used through pregnancy. With the help of this method placental morphology, size, implantation and location can be evaluated, abnormally invasive placenta and other abnormalities can be detected. Although this method is not informative enough in case of certain pregnancy pathologies such as pregnancy hypertension, because the differences are in the placental vasculature, at a deeper anatomical level.

Three-dimensional (3-D) ultrasound on the other hand, can give a more detailed insight to the placenta in a quantitative way, and the analysis of 3-DPD volume files by VOCAL software provides the qualitative assessment of the vascularization and the rate of blood flow.

We analyzed and compared the alterations in vascularization in case of chronic- (CHT), gestational hypertension (GHT), pre-eclampsia (PE), and normal controls (NBP). We also measured placental vascularization in case of pregnancy hypertension complicated with gestational diabetes mellitus (GDM). In this case, we measured an additional parameter as well: AUtPSV, as a potential marker for the prediction of adverse pregnancy outcome in case of $\mathrm{CHT}+\mathrm{GDM}$ or GHT+GDM.

Women with singleton pregnancies were included seen once in second or third trimester at our outpatient clinic at Department of Obstetrics and Gynecology, University of Szeged. The study was carried out between 2014 and 2015. Singleton pregnancies between 20-38 weeks of gestation were divided into six groups: NBP, CHT, CHT+GDM, GHT, GHT+GDM and PE.

An initial 2D conventional ultrasound study provided data about fetal position and presentation, body movements and fetal heart rate, placental localization, umbilical cord insertion, and volume of amniotic fluid. This was followed by the volume acquisition of the placenta (Voluson 730 by GE Medical System, Kretztechnik, Austria, with RAB 2-5 MHz convex transducer) at the insertion point of the umbilical cord. Mercé-type sonobiopsy were used and with the help of VOCAL (4-D View, GE Medical Systems, Austria, version 10.4) 
placental vascularization indices (such as vascularization- (VI), flow- (FI) and vascularization-flow index (VFI)) were calculated.

Data about neonatal outcome and mode of delivery were collected and classified after delivery, histological examination of placentas have been carried out on the basis of the recommendation of The Royal College of Pathologists (UK), and statistical analyses was performed with IBM SPSS Statistics 21.0 for Windows program.

Significant differences were found between pathological placentas examined in case of placental vascularization indices. In case of CHT VI was found significantly higher and FI was found significantly lower compared to NBP which correlates with the same adverse pregnancy outcome rates between CHT and NBP. In case of GHT both VI and FI were found significantly lower compared to NBP and CHT as expected. Placental vascularization indices were even worth in case of PE correlating with the increased adverse pregnancy outcome rates. AUtPSV showed significant differences in pregnancies complicated with GDM.

In conclusion, we can say that 3-DPD examination of placentas, and evaluation of vascularization indices in case of pregnancy hypertension may provide new data about the background patho-mechanisms going on inside the placenta during development. This method can also be useful in the prediction of adverse pregnancy outcomes in case of pregnancy hypertension. 


\section{Introduction}

Hypertension complicating pregnancy is a major cause of maternal and fetal morbidity and mortality. Most of this morbidity is associated with preeclampsia, when high blood pressure is just one aspect of the disease. It has many devastating effects on many organ systems (1).

\subsection{Definition of hypertension}

According to The American College of Obstetricians and Gynecologists: Hypertension in Pregnancy Task Force (2) hypertension is defined as a blood pressure $\geq 140 \mathrm{~mm} \mathrm{Hg}$ systolic or $\geq 90 \mathrm{~mm} \mathrm{Hg}$ diastolic.

As for The Royal College of Obstetricians and Gynecologists (RCOG) (3) the aim is to keep blood pressure lower than $150 \mathrm{~mm} \mathrm{Hg}$ systolic and $100 \mathrm{~mm} \mathrm{Hg}$ diastolic in pregnant women with uncomplicated chronic hypertension.

The guideline of The Canadian College of Obstetricians and Gynecologists (SOGC) was published in 2014 under the name: Diagnosis, Evaluation, and Management of the Hypertensive Disorders of Pregnancy: Executive Summary (2014) (4). This guideline defines as a II-2B recommendation that: 'Hypertension in pregnancy should be defined as an office (or in-hospital) systolic blood pressure $\geq 140 \mathrm{mmHg}$ and/or diastolic blood pressure $\geq 90$ $\mathrm{mmHg}$, based on the average of at least 2 measurements, taken at least 15 minutes apart, using the same arm.'

The International Society for the Study of Hypertension during Pregnancy (ISSHP) published a revised classification for hypertensive disorders in pregnancy in 2014 (5). According to this statement hypertension should be defined as $\geq 140 \mathrm{mmHg}$ systolic or $\geq 90$ $\mathrm{mmHg}$ diastolic.

\subsection{Classification of hypertensive disorders during pregnancy}

Historically there were many attempts to classify hypertension during pregnancy. According to The American College of Obstetricians and Gynecologists: Hypertension in Pregnancy Task Force (2) clinical classification schema for example, we can talk about chronic hypertension, preeclampsia-eclampsia, preeclampsia superimposed upon chronic hypertension, and transient hypertension. 
According to ISSHP's revised statement from 2014 (5), we can divide pregnancy hypertension cases into four main groups: chronic hypertension, gestational hypertension, preeclampsia, and white coat hypertension. The above statement underlines that HELLP syndrome (the combination of hemolysis, elevated liver enzymes and thrombocytopenia) is considered as a more severe form of preeclampsia, and not as an isolated and separate disorder (5).

\subsection{Hemodynamic changes in normal and preeclamptic pregnancy}

It is well known that there are hemodynamic changes that are induced by pregnancy. These changes can alter in case of pregnancy hypertension and can explain the severity and the number of complications occur in these pregnancies.

\subsubsection{Normal pregnancy}

In normal pregnancies, in the systemic arterial side, significant decrease can be detected in systolic and diastolic blood pressure (as early as the $6^{\text {th }}$ weeks of pregnancy) (6). Cardiac output increases by 35-50\% during pregnancy, and at least half of this increase occurs as early as the $8^{\text {th }}$ gestational week $(6,7)$. By $16-20^{\text {th }}$ weeks of gestation this increase in output reaches $50 \%$, and then plateauing until term (6). There are two determinants of cardiac output: heart rate, which will increase until term; and stroke volume, which will increase until $16^{\text {th }}$ weeks of gestation and will plateauing from then $(6,7,8)$.

During normal pregnancy, there is $30-50 \%$ increase in extracellular fluid, plasma and blood volume. Glomerular filtration rate and renal blood flow are also increased (9). Physiological hemodilution can be detected, albumin level is increased. Plasma renin-, angiotensin II- aldosterone level is increased, relative overload of vasodilator components (NO, prostacyclin, and prostaglandin E2) can be detected, level of vasoconstrictor thromboxane A2 is decreased. There is increased extra cellular fluid in the form of physiological edema (“normal” edema) as well (9).

\section{Maternal venous system}

There are changes in the venous system as well, as it should provide enough filling pressure for the increased cardiac output requirements. It can be described by mean circulatory filling pressure (MCFP) $(6,10)$. In animal models significant increase was detected 
in MCFP, which raised the possibility that increased cardiac output is a secondary response for a relative overfilling of the circulatory system $(6,11)$. There is limited data on venous tone regulation as well. Hohmann et al.'s study (12) for example raised the possibility of a denervation supersensitivity. It seems that venous distensibility, in other words compliance, increases during pregnancy (6).

\section{Maternal arterial system}

As a result of increased cardiac output, and decreased blood pressure, there is a significant decrease in total systemic vascular resistance $(6,7)$. It is also important to mention that afterload is a mechanical opposition the heart experiences, and has two components: steady and pulsatile (6).

The pulsatile component is determined by the elastic components of the vessels (13). Pulsatile arterial load can be described by global arterial compliance (describes global reservoir properties), aortic characteristic impedance (describes local reservoir property) and wave propagation and reflection (describe wave propagation and reflection within the arterial tree) (9).

Systemic vascular resistance, the steady component of afterload decreases throughout pregnancy. Global arterial compliance increases, aortic characteristic impedance decreases, and wave propagation is reduced along with a significant delay detected in timing of reflected waves during pregnancy (10).

In conclusion both steady and pulsatile arterial load decrease during pregnancy, thus peripheral vasodilation and generalized relaxation can be detected in peripheral and conduit vessels as well. The decrease in systemic vascular resistance and the increase in cardiac output will result in a slightly decrease in mean arterial pressure (6).

\section{Maternal left ventricle}

The amount of increase in left ventricular mass has been reported between 10-40\% $(8,14,15)$. It is also known, that there is an increase in cross-sectional area of the left ventricular outflow tract (6). As for myocardial contractility it seems, that there is no significant change detectable during pregnancy (6). 


\subsubsection{Preeclampsia}

Normal pregnancy is accompanied by increased blood volume, high cardiac output, and peripheral vasodilation, in other words a low-resistance systemic circulation develops. In case of preeclampsia this status moves towards to a high-resistance state (lower cardiac output, lower blood volume and peripheral vasoconstriction) (6).

In preeclampsia the increase in extracellular fluid, plasma and blood volume is less than in normal pregnancy. Because of increased vascular permeability and peripheral resistance pathological edema ("abnormal" edema) occurs. Glomerular filtration rate and renal blood flow are decreased. There is hemoconcentration in preeclamptic women, their albumin level is decreased, the balance in renin-, angiotensin- aldosterone system is impaired, and relative overload of vasoconstrictors can be detected (9).

\section{Maternal arterial hemodynamics}

In many patients, who developed preeclampsia at late pregnancy, increased mean blood pressure was documented (6).

\section{Maternal arterial properties}

Studies from Hibbard et al. (16) showed that the reservoir capacity of arterial circulation is decreased, and there is lower compliance.

\section{Maternal left ventricle}

According to Lang et al. (17) there is no difference in left ventricular muscle mass and end-diastolic diameter between preeclamptic and normal pregnancies. Despite they found decreased left ventricular performance in PE, it is not pathological, just a normal cardiovascular response to increased afterload (6).

\subsection{The Renin-Angiotensin Aldosterone System in normal pregnancy and preeclampsia}

\subsubsection{Normal pregnancy}

There is significant activation of Renin-Angiotensin Aldosterone System (RAAS) in normal pregnancy (9). Relative overload of prostacyclin and prostaglandin E2 that mediate 
vasodilatation can be detected, while the level of thromboxane A2 which has vasoconstrictive effect is decreased (9). In preeclampsia, this balance is impaired.

\subsubsection{Preeclampsia}

Preeclamptic women have increased sensitivity to angiotensin II, decreased RAAS components and increased serum level of angiotensin II type I receptor activating antibody (AT1-AA) (9). AT1-AA activates AT1 receptor and through a complex signaling process in vascular cells increases for example reactive oxygen species $(9,18)$ and soluble fms-like tyrosine kinase 1 (sFlt-1) (19) production.

\subsection{Platelets in normal pregnancy and preeclampsia}

In normal pregnancies platelet count decreases by $10 \%$, and platelet volume increases compared to non-pregnant population. Platelet aggregation, and intracellular free $\mathrm{Ca}^{2+}$ are increased (20).

In preeclamptic pregnancies platelet volume further increases, while platelet concentration, and lifespan decreases. In PE younger, and larger platelets can be found. Platelet aggregation decreases, resulting in reduced response to adenosine diphosphate (ADP), and vasopressor agents, while intracellular free $\mathrm{Ca}^{2+}$ further increases causing platelet activation (20).

The increased platelet activation is may be extrinsic, resulting from endothelial damage, or at least partially it is intrinsic. One evidence of it is the increased platelet angiotensin II binding sites $(21,22)$.

\subsection{Coagulation in normal pregnancy and preeclampsia}

In normal pregnancy coagulation cascade is activated, as all clotting factors have increased concentration except factor XI and XIII. It seems that in preeclampsia there are many coagulopathic changes (20). For example, in normal pregnancy and in preeclampsia also plasma fibrinogen concentrations are increased, but in case of preeclampsia the turnover of radiolabeled fibrinogen was also increased (and returned to normal level by administering low-dose aspirin) (20). 
3.7. The placentation process in normal pregnancy and pregnancy hypertension

In an uncomplicated pregnancy with normal placenta cytotrophoblasts differentiate by fusing to form syncytiotrophoblasts in floating-, and anchor villi as well. Cytotrophoblasts, that formed cell columns are located at the distal end of villi, and performing interstitial and endovascular invasion. These cells replace the endothelium and the muscular layer of arterioles to enlarge vessel diameter (23). See Figure 1.

Figure 1. a | The blood supply to the human pregnant uterus is shown. b | Normal pregnancy. c | Preeclampsia and fetal growth restriction. (23)

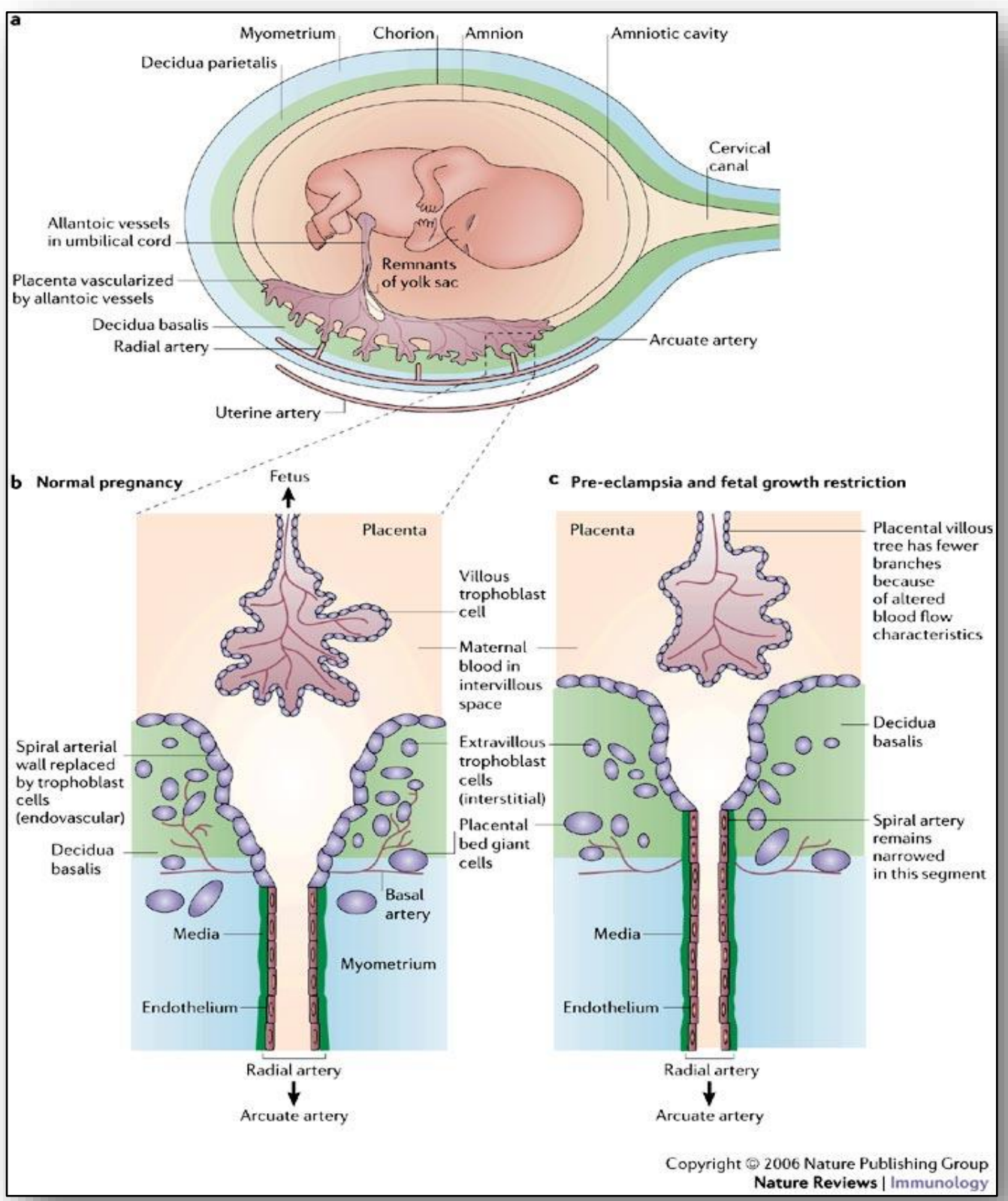


Cytotrophoblast invasion of the uterus in preeclampsia shallow, the endovascular invasion process stacks at the terminal portion of spiral arterioles (24). The interstitial invasion of cytotrophoblasts is also impaired, their invasion is limited to the level of superficial decidua. On the fetal surface, the placental villous tree has fewer branches (23). See Figure 1.

Because of the above-mentioned alterations preeclamptic placentas do not undergo the physiological changes, and the mean diameter of myometrial vessels are going to be less than half compared to normal pregnancies (25). See Figure 2.

Figure 2. Schematic placental diagram with sites of action for major patterns of injury (26)

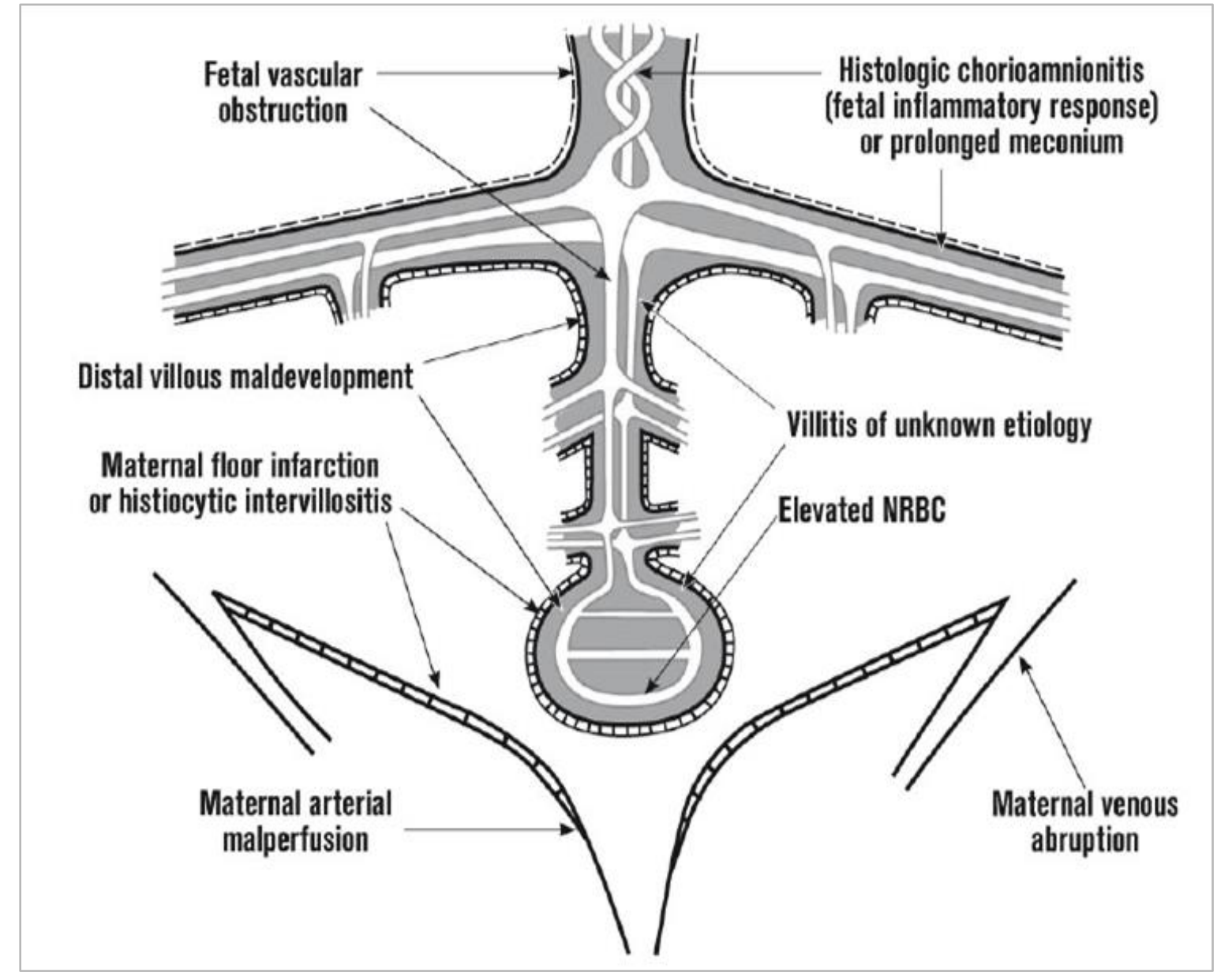

Hypertensive disorders of the mother are linked to in utero hypoxia. Figure 3 shows a characteristic evolutionary pattern of acute hypoxic membrane and villous lesions (27). 
Figure 3. Evolution of acute hypoxic membrane and villous lesions. A: Evolution of membrane laminar necrosis. B: Evolution of villous infarction. (27)

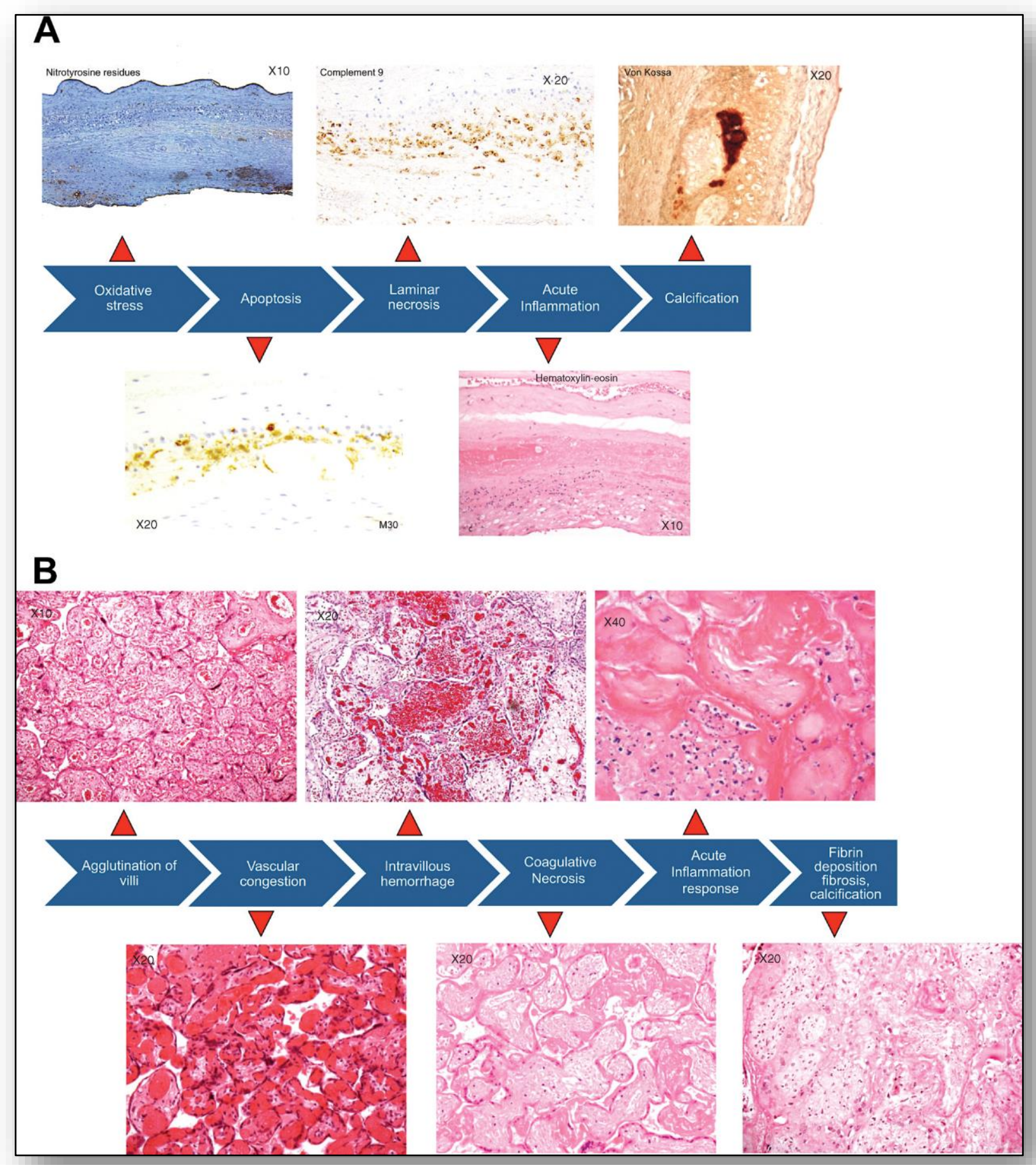




\subsection{The role of angiogenic factors}

Recent studies showed strong correlations between pro- and antiangiogenic factor level changes in pregnancy hypertension especially in PE. These angiogenic factors can explain certain processes of the etiology, can predict the development and may be a useful target in the treatment of PE.

\subsubsection{About angiogenic factors}

The first angiogenic factor was discovered in 1971, in tumor tissue, and named as tumor angiogenic factor (TAF) (28). Dvorak et al. found vascular permeability factor (VPF) in 1983, which increased capillary permeability and extravasation (29). In 1989 vascular endothelial growth factor (VEGF) was isolated, that stimulates vascular endothelial cell cleavage (30). Later VEGF isoforms were discovered: Flt-1, Flk-1 and Flt-4 (31). The studies of Plate et al. (32) showed that hypoxia is a trigger in angiogenesis of tumor tissue, as VEGF expression was the highest in ischemic parts of the tissue. Placental growth factor (PIGF) was discovered in 1991 (33). Karumanchi et al. found that the level of soluble form of Flt-1 (sFlt-1) is increased in pregnant women's serum with PE, and decreases after delivery parallelly with the symptoms relieve (34).

Earlier publications reported about the role of PIGF and its functional inhibitor sFlt-1 in PE. As sFlt-1 is a soluble receptor for PlGF, it binds PlGF in maternal blood thus free PlGF serum level decreases. In PE the antiangiogenic sFlt-1 level increases, while the level of proangiogenic PIGF decreases in maternal serum $(34,35)$.

Rigó et al. (36) showed, that in all forms of pregnancy hypertension, the serum level of PIGF is significantly lower compared to uncomplicated pregnancies through pregnancy. The lowest level of PIGF was reported in PE and HELLP (36). Several studies found correlations between the severity of PE, and the serum concentration of angiogenic factors $(37,38)$. After delivery, the level of sFlt-1 and PIGF returns to normal level, parallelly with the symptoms, that relieve $(34,39)$.

Animal (rat) models verified these findings, as artificial decrease in uteroplacental perfusion triggered preeclamptic symptoms and increased sFlt-1 level was detected (40). During another study adenoviruses containing sFlt-1 were injected into pregnant mice, and increased blood pressure and decreased platelet count were detected (41). 
Recent studies showed the prognostic potential of sFlt-1/PlGF ratio in preeclamptic patients $(42,43)$. Verlohren et al. tested the hypothesis that sFlt-1/PIGF ratio is able to identify preeclamptic women at risk for imminent delivery (43). In pregnancy hypertension patient's sFlt-1 level is increased prior to clinical symptoms and also correlates with the severity of the disease, while PIGF levels are significantly decreased. Recent clinical studies $(42,43)$ suggest that sFlt-1 and PlGF, especially when sFlt-1/PIGF ratio is calculated, may serve to diagnose and predict PE and its related complications.

\section{Angiogenic factors in the prediction of preeclampsia}

No single screening test used for detecting or predicting preeclampsia (44) has gained widespread acceptance into clinical practice. Instead, its value seems to be in increasing the predictive value of panels of tests, which include other clinical measurements such as mean arterial pressure (MAP), uterine artery pulsatility index (UTPI) in combination with sFlt-1/PlGF ratio (45).

Gallo et al. (46) found that using the combination of MAP, UTPI, PIGF and sFlt-1, as a risk model applied between 19 and 24 weeks of gestation can detect $78 \%$ of early and intermediate PE cases at a 5\% false positive rate, but this risk model can only detect $33 \%$ of late PE cases. Tsiakkas et al. (47) found that using the combination of MAP, UTPI, PIGF and sFlt-1, as a risk model applied between 30-34 weeks of gestation can detect $98 \%$ of intermediate PE cases at a $5 \%$ false positive rate, but this risk model can only detect $54 \%$ of late PE cases. Andrietti et al. (48) found that using the combination of MAP, UTPI, PIGF and sFlt-1, as a risk model applied between 35 and 37 weeks of gestation can detect $75 \%$ of late PE cases at a 5\% false positive rate. Dragan et al. (49) Compared sFlt-1-PlGF ratios measured between 31-34 and 35-37 weeks of gestation and found that the ratio is useful to predict PE for 1 week in advance but for longer period it's accuracy decreases.

\section{Angiogenic factors and smoking}

Smoking during pregnancy increases the chance of spontaneous abortions, intrauterine death, placental abruptions, preterm delivery and IUGR, but decreases the development of PE (50). In uncomplicated pregnancies serum sFlt-1 level was significantly lower compared to non-smoking controls, and in PE pregnancies serum sFlt-1 level was significantly lower compared to non-smoking PE pregnancies. This study showed that smoking protects pregnancies from developing PE through angiogenic factors (51). 


\subsection{Gestational diabetes mellitus}

In Hungary, the prevalence of gestational diabetes mellitus (GDM) is 6\%-9.5\% (52). Pregnancies complicated with GDM have increased risk for macrosomia (53), perinatal complications (such as birth injuries, brachial plexus injuries, perinatal death, and neonatal hypoglycemia) (54), and congenital malformations (55). The most common risk factors associated with GDM include: non-Caucasian women; maternal age over 35 years; pregestational obesity $(\mathrm{BMI}>30 \mathrm{~kg} / \mathrm{m} 2)$; familial diabetes; hypertension; glycosuria during pregnancy; previous birth of a macrosomia (birth weight at term $\geq 4000$ grams), or large for gestational age (LGA) (above the 90 percentile); fetal malformation or intrauterine death in previous pregnancy; habitual abortion (56).

As glucose homeostasis depends on the balance between insulin (that stimulates cellular uptake of plasma glucose), and glucagon and cortisol (that stimulates glucose production and excretion to plasma), alterations in this balance can lead to glucose intolerance, and increased glucose levels during pregnancy $(57,58)$.

Human placenta produces cortisol, human placental lactogen, progesterone, human chorionic gonadotropin, and insulysin. These insulin antagonists increase maternal serum glucose level (58). If pancreatic B islet cells are unable to balance out increased glucose levels of pregnant mother by producing sufficient insulin, or maternal insulin resistance occurs, gestational diabetes mellitus, a state of hyperglycemia develops (59).

\section{Placental morphology in gestational diabetes mellitus}

Various morphological and functional changes can be observed in placentas of pregnancies complicated with gestational diabetes mellitus (57). The overproduction of extracellular matrix worsened by interstitial edema leads to increased tissue mass in the placenta (57).

In the diabetic placenta, the most conspicuous histological findings are villous immaturity and the presence of cytotrophoblasts. The prominence of cytotrophoblasts may be the result of their fusion to form syncytiotrophoblasts (57). Basal membranes of syncytiotrophoblasts and endothelium are thickened in GDM, resulting in a significant reduction in diffusion capacity for oxygen of villi (57).

There are three stages of placental development: 1. implantation, proliferation and invasion; 2. villus differentiation; and 3. placental mass expansion, overlapping by two phases of trophoblast and endothelium proliferation. See Figure 4. Any insult of the diabetic 
environment early in pregnancy (pre-GDM) will have long-term effects, while insult of the diabetic environment at a later stage of pregnancy (GDM) will only have short-term effects, thus alterations will occur in function, rather than in structure (60).

Figure 4. Three stages of placental development; trophoblast and endothelium development; and diabetes mellitus. (60)

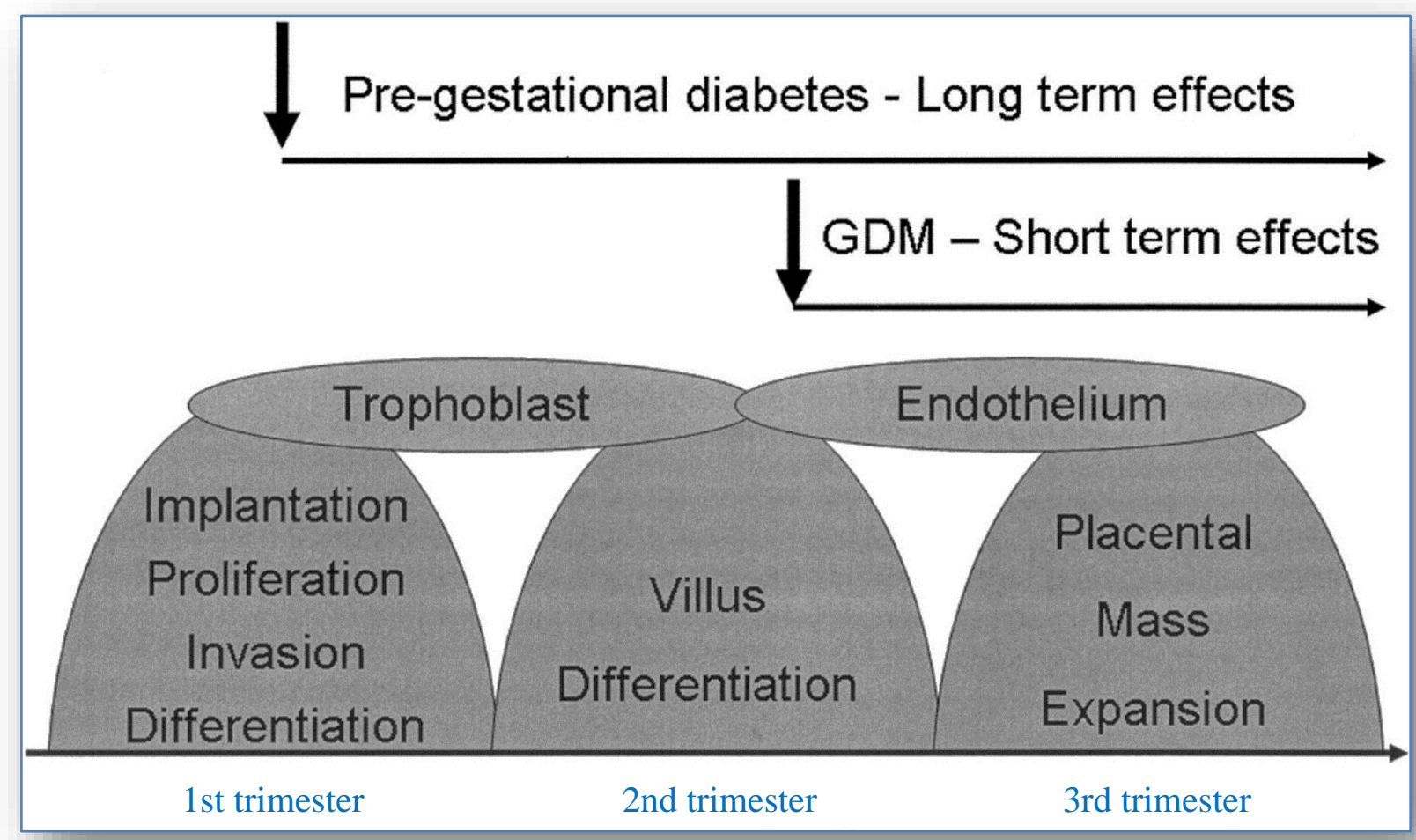

\subsection{Intrauterine growth restriction}

Growth restricted fetuses by definition are fetuses with estimated fetal weight below the 10th percentile for gestational age $(61,62)$. In Hungary the frequency of IUGR is between 8$10 \%$, as in other parts of the world $(61,63)$. Perinatal complications are 3-4 times more frequent in IUGR, than in eutrophic newborns. As $30 \%$ of still-born have IUGR (60), it is a clinically significant perinatal problem $(64,65)$.

Reasons that lead to the development of IUGR can be divided into three main groups: maternal, fetal and uteroplacental (65). See Table 1. 
Table 1. Maternal, fetal and placental factors that are responsible for the development of IUGR. (65)

\begin{tabular}{|c|c|c|}
\hline \multirow{25}{*}{$\begin{array}{l}\text { Maternal } \\
\text { factors }\end{array}$} & \multirow[t]{4}{*}{ Demographics } & extreme of maternal age \\
\hline & & race $\quad-\quad-1-1-1$ \\
\hline & & low pre-pregnancy weight \\
\hline & & poor maternal weight gain \\
\hline & \multirow{2}{*}{ Obstetrical } & short inter-pregnancy interval \\
\hline & & prior history of small for gestational age (SGA) \\
\hline & \multirow[t]{4}{*}{ Behavioral/environmental } & smoking \\
\hline & & alcohol \\
\hline & & drug use \\
\hline & & high altitude \\
\hline & \multirow[t]{11}{*}{ Systemic disease } & $\begin{array}{l}\text { hypertension (chronic hypertension, } \\
\text { preeclampsia) }\end{array}$ \\
\hline & & pregestational Diabetes \\
\hline & & renal disease \\
\hline & & anemia \\
\hline & & pulmonary disease \\
\hline & & congenital heart disease \\
\hline & & autoimmune disease \\
\hline & & antiphospholipid syndrome \\
\hline & & $\begin{array}{l}\text { GI disease (Crohn's disease, ulcerative colitis, } \\
\text { gastric bypass, malabsorption) }\end{array}$ \\
\hline & & malnutrition \\
\hline & & transplant recipient (Renal) \\
\hline & \multirow[t]{4}{*}{ Others } & artificial reproductive technologies (ART) \\
\hline & & uterine factors (fibroid, müllerian anomalies) \\
\hline & & medications (anticonvulsants, beta blockers) \\
\hline & & angiotensin gene mutation \\
\hline \multirow[t]{15}{*}{ Fetal factors } & \multirow[t]{4}{*}{ Genetic } & trisomy $21,18,13$ \\
\hline & & turner's syndrome \\
\hline & & deletion of chromosome 4,5 \\
\hline & & genetic syndromes \\
\hline & \multirow[t]{4}{*}{ Congenital malformations } & congenital heart disease \\
\hline & & CDH \\
\hline & & abdominal wall defect \\
\hline & & anencephaly \\
\hline & \multirow{6}{*}{ Infection } & TORCH \\
\hline & & malaria \\
\hline & & chlamydia, \\
\hline & & mycoplasma, \\
\hline & & listeria, \\
\hline & & tuberculosis \\
\hline & Others & multiple pregnancy \\
\hline \multirow{11}{*}{$\begin{array}{l}\text { Placental } \\
\text { factors }\end{array}$} & \multirow[t]{9}{*}{ Placenta } & placental abruption \\
\hline & & placenta accreta \\
\hline & & placental infarction \\
\hline & & circumvallate placenta \\
\hline & & confined placental mosaicism \\
\hline & & placental hemangioma \\
\hline & & placental chorangioma \\
\hline & & diffuse chronic villitis \\
\hline & & fetal villous obliteration \\
\hline & \multirow[t]{2}{*}{ Umbilical chord } & velamentous cord insertion \\
\hline & & single umbilical artery (SUA) \\
\hline
\end{tabular}


As the adaptive capacity of the fetus decreases, circulatory redistribution will occur (,heart and brain sparing effect”) (66). In case the fetal circulation further decreases, the physiological compensatory mechanisms will be exhausted, thus hypoxic stress will develop causing hypoglycemia, acidosis, thrombocytopenia and oliguria in the fetus. The abnormalities of uteroplacental circulation lead to fetal hypoxia: pO2 decreases, depot of glucose and glycogen reduces. As a result of that, the fetus adapts to hypoxia and hypoglycemia, stops in weight gain, and reduces fetal activity (66). 


\section{Hypothesis}

1. At the beginning of the present study we hypothesized that there is negative correlation between 3-DPD vascularization indices and the severity of pregnancy hypertension type with which the pregnancy is complicated.

2. We also hypothesized that there is correlation between AUtPSV values and the presence of gestational diabetes, as a complication, in case of pregnancy hypertension.

\section{Aims of the investigation}

The aims of the present study were as follows:

1. To evaluate and compare 3-DPD placental vascularization indices in case of case group of pregnancy hypertension and control group of normal blood pressure pregnancies.

2. To evaluate and compare 3-DPD placental vascularization indices between pathological groups of chronic-, gestational hypertension and preeclampsia.

3. To test the hypothesis that there is negative correlation between 3-DPD placental vascularization indices and the severity of pregnancy hypertension type.

4. To compare 3-DPD placental vascularization indices and maternal characteristics between pregnancy hypertension types (CHT, GHT and PE).

5. To compare 3-DPD placental vascularization indices and fetal characteristics between pregnancy hypertension types (CHT, GHT and PE).

6. To compare 3-DPD placental vascularization indices and neonatal characteristics between pregnancy hypertension types (CHT, GHT and PE).

7. To compare 3-DPD placental vascularization indices and adverse pregnancy outcome rates between pregnancy hypertension types (CHT, GHT and PE).

8. To test the hypothesis that there is correlation between AUtPSV values and the presence of gestational diabetes, as a complication, in case of pregnancy hypertension.

9. To evaluate 3-DPD vascularization indices and AUtPSV in case of pregnancy hypertension complicated with gestational diabetes mellitus (CHT+GDM, GHT+GDM).

10. To compare prenatal ultrasonographic findings (vascularization-, flow- and vascularization-flow index) of the placentas, from pregnancy hypertension case groups, to the severity of histological findings following delivery. 


\section{Materials and methods}

We performed a prospective, randomized, control study of placental vascularization indices and uterine artery peak systolic velocity. We included women with singleton pregnancies seen once in second or third trimester at our outpatient clinic at University of Szeged, Faculty of Medicine, Department of Obstetrics and Gynecology, in Szeged. Our study was carried out between 2014 and 2016 in accordance with the Code of Ethics of the Declaration of Helsinki for scientific research involving humans, and our study was approved by the institutional research ethics committee (No.: 32/2014). Informed consent was signed by the observed person after a detailed and clear explanation about the conditions and aims of the survey.

\subsection{Inclusion criteria}

In our study, we analyzed singleton pregnancies between 20-38 weeks of gestation, which were divided into six groups as you can see in Table 2. Gestational age was determined on the basis of the first day of the last menstrual period and on the basis of the first trimester ultrasound biometry (biparietal diameter (BPD) and crown-rump length (CRL)).

Table 2. Groups of pregnant women and the number of cases examined

\begin{tabular}{|l|l|c|}
\hline Groups of pregnant women & No. \\
\hline NBP & group of pregnant women with normal blood pressure & 109 \\
\hline CHT & group of pregnant women with chronic hypertension & 43 \\
\hline CHT+GDM & $\begin{array}{l}\text { group of pregnant women with chronic hypertension complicated with gestational } \\
\text { diabetes mellitus }\end{array}$ & 25 \\
\hline GHT & group of pregnant women with gestational hypertension & 57 \\
\hline GHT+GDM & $\begin{array}{l}\text { group of pregnant women with gestational hypertension complicated with gestational } \\
\text { diabetes mellitus }\end{array}$ & 23 \\
\hline PE & \begin{tabular}{l} 
group of pregnant women with pre-eclampsia \\
\hline
\end{tabular}
\end{tabular}

\subsection{Exclusion criteria}

Exclusion criteria included multiple pregnancies; enlarged ( $\geq 3 \mathrm{~mm})$ nuchal translucency from $11+0$ to $13+6$ weeks of gestation; thrombophilia; molar pregnancy; structural or chromosomal anomaly and fetal abnormalities (with 1 month follow-up after delivery); abnormally invasive placenta; placenta previa; self-reported drug, alcohol, caffeine or nicotine abuse; exposure to circulatory medications (calcium dobesilate, oxerutin); systemic diseases (vasculitis, HIV infection etc.); or not signing the consent form. 


\subsection{Diagnostic criteria for hypertension}

High blood pressure (>140 $\mathrm{mm} \mathrm{Hg}$ systolic or $>90 \mathrm{~mm} \mathrm{Hg}$ diastolic) was defined on the basis of the International Society for the Study of Hypertension in Pregnancy (ISSHP) (3). Blood pressure was measured (BP A100 PLUS, Microlife AG, Windau, St. Gallen, Switzerland) three times on each occasion. Patients in the case groups had ongoing antihypertensive therapy with oral alpha-methyldopa (Dopegyt, EGIS Pharmaceuticals 105 PLC., Budapest, Hungary) and they had dietary salt restrictions according to the Hungarian guidelines (67).

We used the revised classification for hypertensive disorders in pregnancy based on ISSHP (5). See Table 3.

Table 3. Classification for hypertensive disorders in pregnancy (ISSHP 2014) (5)

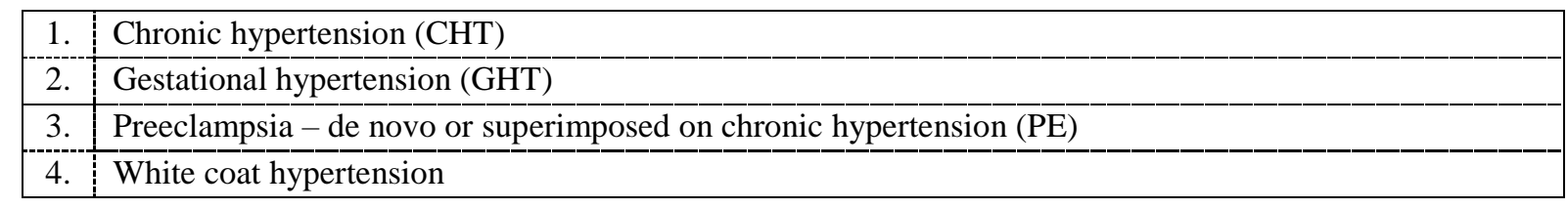

Inclusion criteria for CHT was high blood pressure pre-dating pregnancy. As many women did not have their blood pressure measured before pregnancy, we relied on the first trimester blood pressure according to ISSHP (5) when defining high blood pressure in these women.

Inclusion criteria for GHT was new onset of hypertension after $20^{\text {th }}$ weeks of gestation, for which it was important to have normal blood pressure documented either before pregnancy or at least in early pregnancy before pregnancy-related decrease in blood pressure occurred (5).

\subsubsection{Diagnostic criteria for preeclampsia}

In the diagnosis of PE we applied the definition of ISSHP (5), which defines PE as a combination of new onset of hypertension, that occurs after $20^{\text {th }}$ weeks of gestation and the coexistence of one or more of the following new-onset conditions collected in Table 4.: 
Table 4. List of coexisting new-onset conditions in case of pre-eclampsia (ISSHP 2014) (5)

\begin{tabular}{|c|c|c|}
\hline 1. & $\begin{array}{l}\text { proteinuria (spot urine prote } \\
\text { dipstick testing) }\end{array}$ & creatinine $>30 \mathrm{mg} / \mathrm{mmol}$ or $>300 \mathrm{mg} /$ day or at least $1 \mathrm{~g} / \mathrm{L}\left[{ }^{\prime} 2+{ }^{\prime}\right]$ on \\
\hline \multirow[t]{4}{*}{2.} & \multirow[t]{4}{*}{ maternal organ dysfunctions } & renal insufficiency (creatinine $>90 \mathrm{umol} / \mathrm{l}$ ) \\
\hline & & $\begin{array}{l}\text { liver involvement (elevated transaminases }- \text { at least twice upper limit of } \\
\text { normal } \pm \text { right upper quadrant or epigastric abdominal pain) }\end{array}$ \\
\hline & & $\begin{array}{l}\text { neurological complications (eclampsia, altered mental status, blindness, } \\
\text { stroke, hyperreflexia accompanied by clonus, severe headaches } \\
\text { accompanied by hyperreflexia, persistent visual scotomata) }\end{array}$ \\
\hline & & $\begin{array}{l}\text { hematological complications (thrombocytopenia - platelet count }<150 \\
\text { G/1, DIC, or hemolysis) }\end{array}$ \\
\hline 3. & \multicolumn{2}{|c|}{ Uteroplacental dysfunction in the form of intrauterine growth restriction (IUGR)* } \\
\hline
\end{tabular}

\subsection{Diagnostic criteria for GDM}

GDM was defined on the basis of the recommendation of the World Health Organization (HAPO) 2010 (68), which correlates with the guideline of the Hungarian College of Obstetricians and Gynecologists (52).

In our study patients are screened with oral glucose tolerance test (OGTT) containing 75 mg oral carbohydrate. Maternal serum glucose level (sample tube used contained potassium oxalate and sodium fluoride/Na2 - EDTA) was measured at 0 min. and after 2 hours.

Patients with high risk for GDM (Table 5.) (69) were screened with OGTT between 1216 weeks of gestation, and in case of a negative test result OGTT was automatically repeated between 24-28 weeks of gestation. In case of low risk for GDM patients were screened between 24-28 weeks of gestation.

Table 5. The most common risk factors for gestational diabetes mellitus (69)

\begin{tabular}{|c|c|}
\hline \multirow[t]{6}{*}{ Present pregnancy } & non-Caucasian women \\
\hline & high maternal age ( $>35$ years) \\
\hline & obesity $(\mathrm{BMI}>30 \mathrm{~kg} / \mathrm{m} 2)$ \\
\hline & familial diabetes \\
\hline & chronic hypertension \\
\hline & glycosuria during pregnancy \\
\hline \multirow[t]{5}{*}{ Previous pregnancy } & intrauterine death \\
\hline & habitual abortion \\
\hline & previous birth of a macrosomia (birth weight at the term is $\geq 4000$ grams) \\
\hline & large for gestational age neonate (above the 90 percentile) \\
\hline & former fetal malformation \\
\hline
\end{tabular}

Diagnostic criteria for GDM are listed in Table 6 (68). 
Table 6. Diagnostics criteria for gestational diabetes mellitus (HAPO Study 2010) (68)

\begin{tabular}{|c|l|}
\hline 1. & fasting blood glucose level is between $5,1-6,9 \mathrm{mmol} / \mathrm{l}$ \\
\hline 2. & normal fasting glucose, but postprandial 120 -minute value is between $8,5-11,0 \mathrm{mmol} / \mathrm{l}$ \\
\hline
\end{tabular}

Groups CHT+GDM and GHT+GDM consisted of patients who had dietary sugar and salt restriction in addition to the antihypertensive therapy. Their blood glucose and $\mathrm{HgAlc}$ levels were in normal range. Those patients, in which introduction of insulin therapy was needed, were excluded from the study. All pregnant women with GDM had normal glycemic response. We used $\mathrm{HgA1c}$ for GDM follow up. Body mass index (BMI) was defined as follows: underweight: $<19 \mathrm{~kg} / \mathrm{m} 2$; obese: $>30 \mathrm{~kg} / \mathrm{m} 2$.

\subsection{Three-dimensional ultrasound}

Improvements in three-dimensional (3D) ultrasound have allowed us to obtain and study volumes from different organs, such as the human placenta (Figure 5.) more precisely (70), and the color map provided by power Doppler has made the study of vessels with low resistance much easier (71). The combination of these techniques has made it possible to study the morphology of the vascular tree and to quantify the total blood flow of the placenta (72).

Figure 5. Interface of VOCAL software presenting the measurement of placental volumetria. $\left(14^{\text {th }}\right.$ week of gestation)

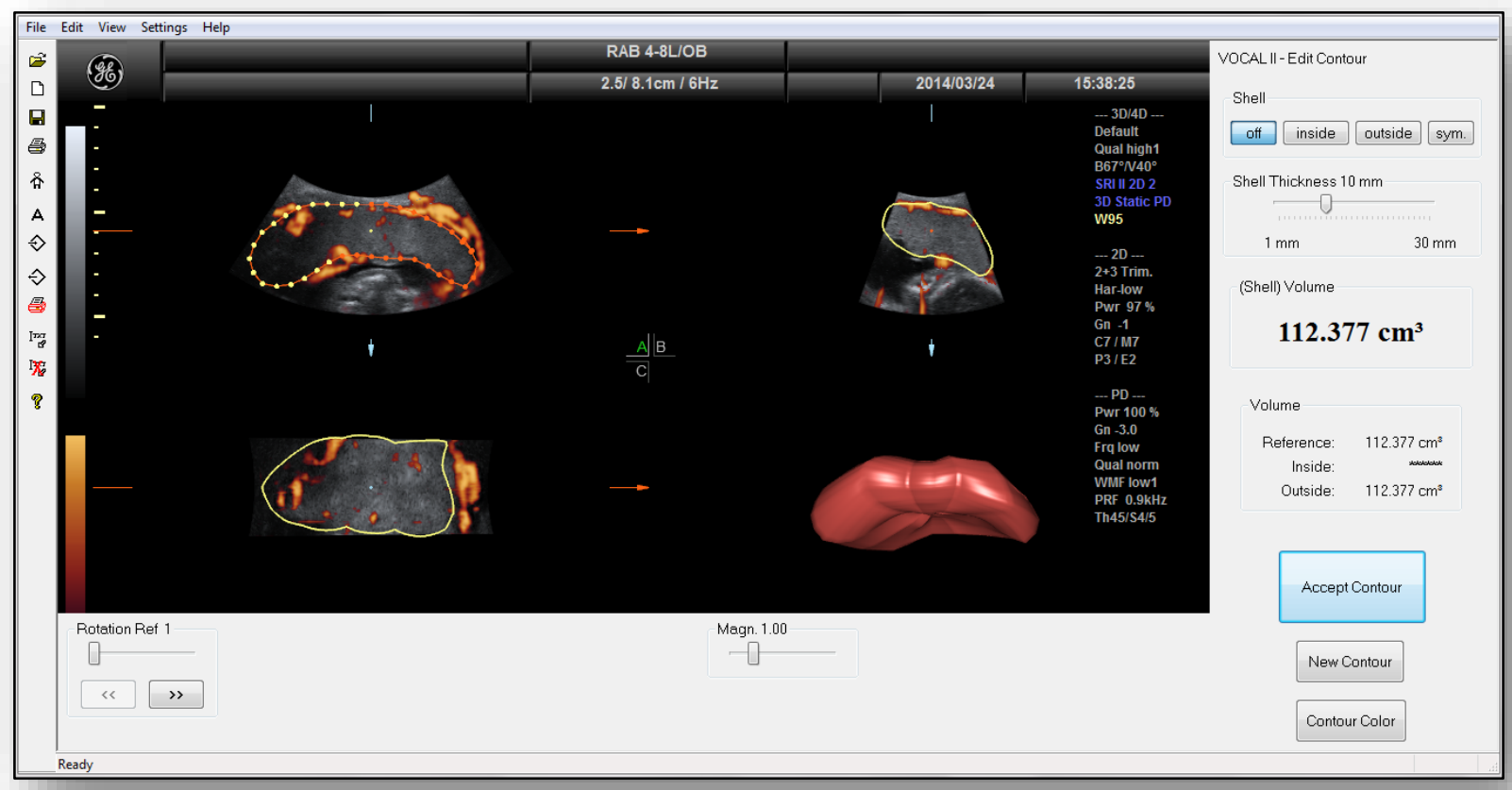




\subsubsection{Mercé-type sonobyopsy}

Mercé-type placental sonobyopsy is a reproducible, validated method for obtaining representative sample of the placental tree, which - contrary to other methods - is applicable throughout the whole pregnancy when the entire placenta needs to be visualized $(73,74)$. This method is a valid alternative for the evaluation of the placental vascular tree when visualization of the entire placenta is not possible (75). See Figure 6.

Figure 6. Interface of VOCAL software presenting placental sonobyopsy at umbilical cord insertion (32 $2^{\text {nd }}$ week of gestation)

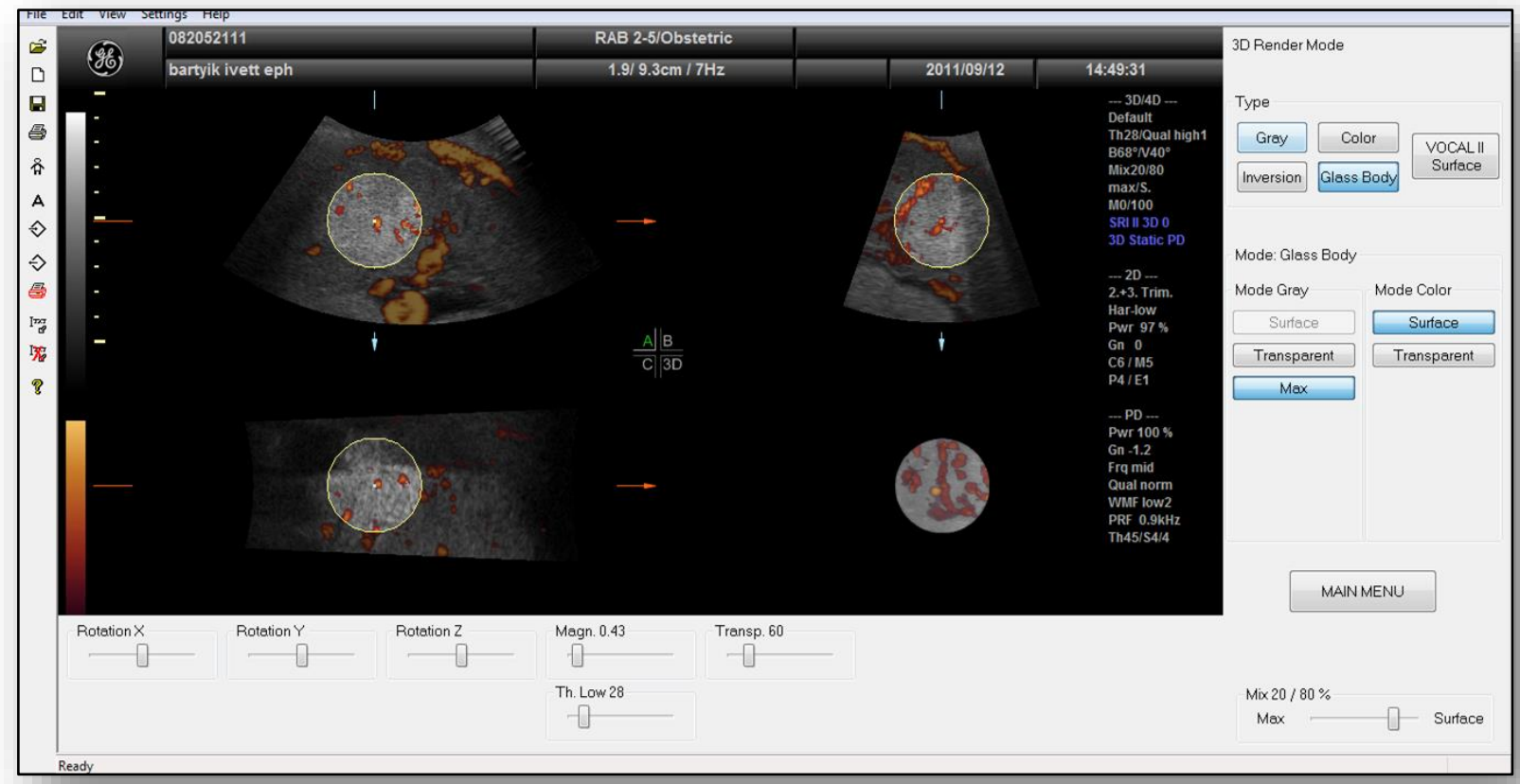

\subsubsection{Virtual Organ Computer-Aided Analyses}

Volume files were analyzed using the virtual organ computer-aided analysis (VOCAL) software pertaining to the computer software 4D VIEW (GE Medical Systems, Austria, version 10.4) by an expert in 3D analysis.

\subsubsection{Placental vascularization indices}

The VOCAL software automatically calculates the color scale values in a histogram (See Figure 6.), and the vascularization indices (vascularization index (VI), flow index (FI) and 
vascularization flow index (VFI)) from the acquired spherical sample volume in all cases (73). See Table 7.

Table 7. Placental vascularization indices

\begin{tabular}{|l|c|l|}
\hline Vascularization index & VI & $\begin{array}{l}\text { denotes the ratio of color-coded voxels to all voxels within the volume } \\
\text { and is expressed as a percentage }\end{array}$ \\
\hline Flow index & FI & $\begin{array}{l}\text { represents the mean power Doppler signal intensity from all color-coded } \\
\text { voxels }\end{array}$ \\
\hline Vascularization-flow index & VFI & $\begin{array}{l}\text { derived from VI and FI through a complex mathematical formula } \\
\text { (Figure 7) }\end{array}$ \\
\hline
\end{tabular}

* voxel is the smallest unit of 3D volume files like pixel is the smallest unit of 2D files.

Figure 7. Calculation of placental vascularization indices: VI, FI and VFI.

$$
\begin{aligned}
& M G=\frac{\sum_{g=1}^{100} g \cdot h g(g)}{\sum_{g=1}^{100} h g(g)} \\
& V I=\frac{\sum_{c=1}^{100} h c(c)}{\sum_{g=1}^{100} h g(g)+\sum_{c=1}^{100} h c(c)}(\mathrm{ANGIO}) \\
& F I=\frac{\sum_{c=1}^{100} c \cdot h c(c)}{\sum_{c=1}^{100} h c(c)}(\mathrm{ANGIO}) \\
& V F I=\frac{\sum_{c=1}^{100} c \cdot h c(c)}{\sum_{g=1}^{100} h g(g)+\sum_{c=1}^{100} h c(c)}(\mathrm{ANGIO}) \\
& V F I=V_{\times} F I(\mathrm{ANGIO})
\end{aligned}
$$

6.6. Management of the examinations

All patients were scanned in a semi recumbent position with the help of Voluson 730 system (RAB 2-5 MHz convex transducer; GE Healthcare Austria, Tiefenbach, Austria). Same instrumental settings were used in all cases ('Obstetrics/2-3 trimester' in 2D mode). 


\subsubsection{Fetal biometry}

Examination started with fetal biometry in 2D mode ultrasound to assess biparietal diameter (BPD), head circumference (HC), abdominal circumference (AC), femur length (FL) and to calculate estimated fetal weight (EFW) with the help of formula B of Hadlock (76), followed by color Doppler study of the uterine arteries (77).

\subsubsection{Early diastolic notch}

We visualized the insonation of uterine arteries at their crossover with the iliac arteries in both sides, that are the exact anatomical points for the measurement (78). (See Figure 8.)

Figure 8: Insonation of the uterine artery /the anatomical point of the measurement/ at the crossover with the iliac artery /left/, and pathological flow velocity waveform from the uterine artery at $24^{\text {th }}$ weeks of gestation: early diastolic notch is indicated with a yellow arrow, and orange arrow indicates a decrease in late diastole /right/. (79)
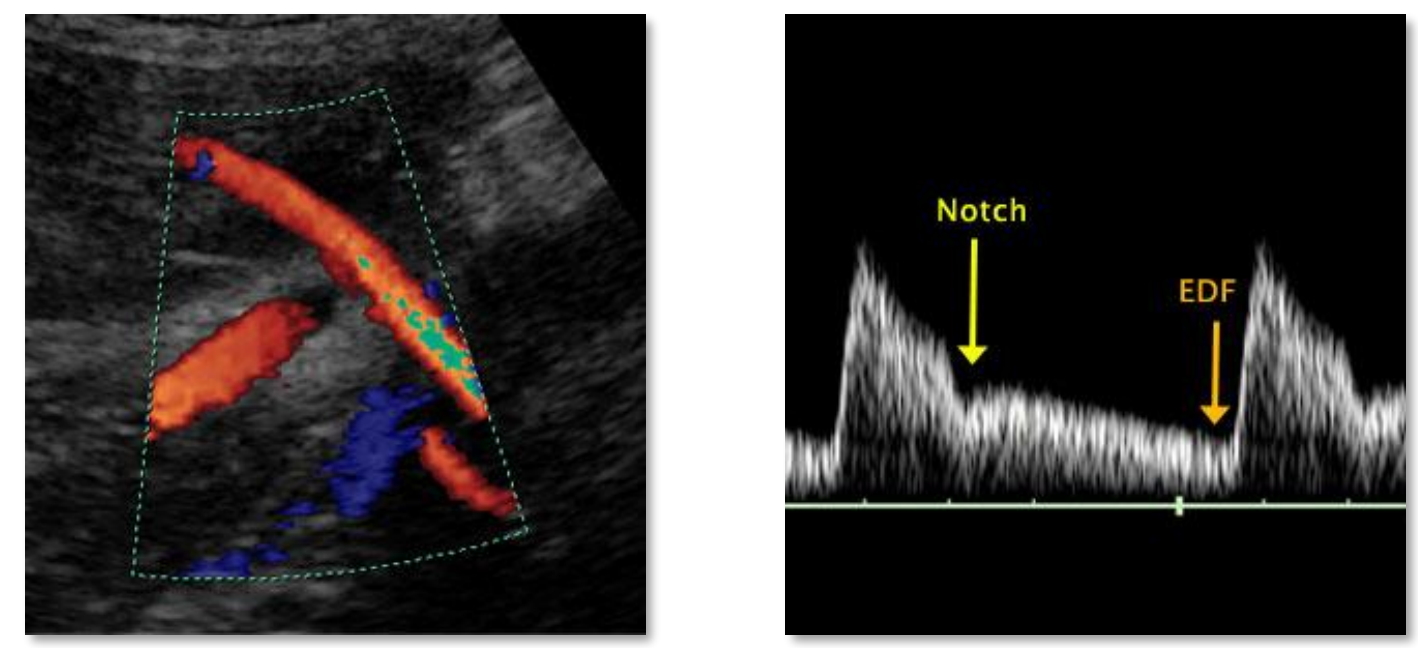

The presence of early diastolic notch in uterine arteries (from $20^{\text {th }}$ weeks of gestation) is used to predict preeclampsia and IUGR although the sensitivity for mild preeclampsia is only $29 \%$, and the sensitivity for birth weight below the $10^{\text {th }}$ percentile is $38 \%$ (78).

\subsubsection{Measurement of uterine artery peak systolic velocity}

To identify the uterine arteries, we obtained a sagittal section of the uterus, and used color flow mapping for AUtPSV (cm/s). (Figure 9.) Then we applied color Doppler with the 
sampling gate set at $2 \mathrm{~mm}$. The angle of insonation was $<30^{\circ}$ and we recorded at least three consecutive uniform waveforms (77). The impact of placentation on AUtPSV was ruled out by calculating the average value of the left and right uterine artery, and pulsatility index (PI) was measured as well (80).

Figure 9. Measurement of uterine artery peak systolic velocity (AUtPSV). Ultrasound picture was taken from the sagittal section of the uterus with color flow mapping and pulsed wave Doppler was applied. The value of AUtPSV is highlighted in red.

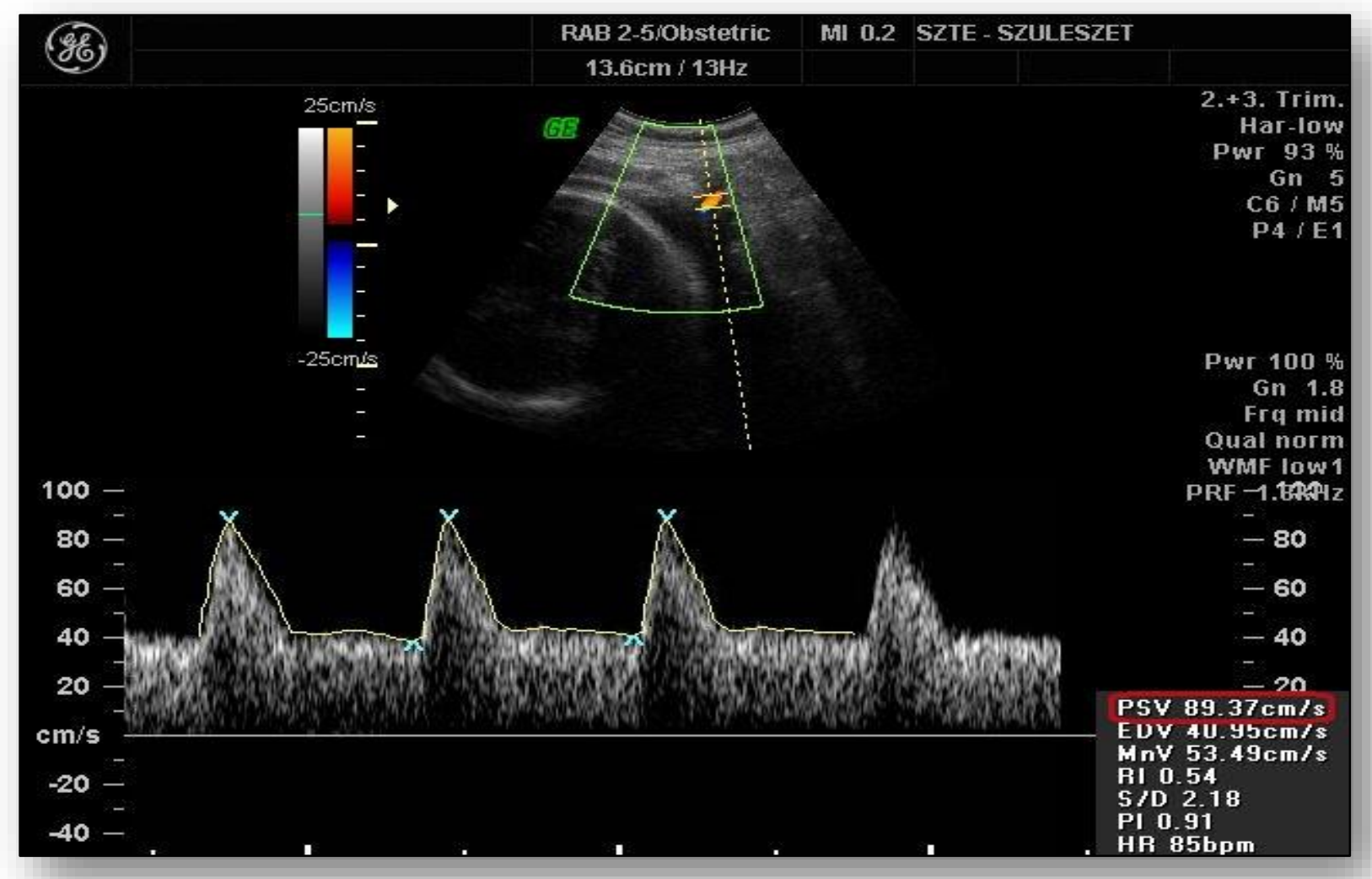

\subsubsection{Volume acquisition}

The next step was the 3D scan of the placenta at the insertion point of the umbilical cord. We used 3D rendering mode, in which the color and gray value information was processed and combined to give a 3D image (mode cent: smooth, 4/5; FRQ, low; quality, 16; density, 6; enhance, 16; balance, 150; filter, 2; actual power, $2 \mathrm{~dB}$; pulse repetition frequency, 0.9) (81). Power Doppler window (pulse repetition frequency at $900 \mathrm{~Hz}$ and wall filter of $50 \mathrm{~Hz}$ ) was placed over the placenta, mapping the vascular tree from basal to chorionic plates, as this technique shows higher sensitivity because it is based on amplitude instead of mean frequencies to depict the vascular tree (82). Moreover, color mapping is independent of the 
angle of insonation and does not show 'aliasing' $(71,83)$. However, it is more sensitive to patient movements, so the volumes should be acquired while avoiding any probe or patient movements; otherwise artifacts could be present.

The 3D static volume box was placed over the highest villous vascular density zone at umbilical cord insertion (73). The sweep angle was set at maximum $70^{\circ}$. The three planes of the acquired placental volume were explored to localize the zone where the highest vascular density was found by power Doppler mode $(73,84)$. Volume acquisition was made during a time interval varying from 5 to $10 \mathrm{~s}$ in the absence of fetal movements and with the mother staying as still as possible. We used fast-low resolution acquisition to avoid any kind of artifacts (73). The variation in acquisition time was also dependent on the size of the volume box, and it correlated with the age of gestation.

\subsubsection{Calculation of 3-dimensional power Doppler indices}

We used Mercé-type sono-biopsy (73), a reproducible, valid alternative for evaluation of the vascular tree of the entire placenta $(75,85)$. Volume files were analyzed using the virtual organ computer-aided analysis (VOCAL) software. The spherical sample volume was $28 \mathrm{~mL}$ constantly. See Figure 6.

The VOCAL software automatically calculated the color scale values in a histogram (Figure 10.), and the vascularization indices.

The 2D and 3D ultrasound acquisitions were performed at the same time, and 3D volume files were analyzed by VOCAL at a later time. The ultrasound images of 2D and 3D scans were stored on a hard disk (HD). 
Figure 10. Interface of VOCAL software presenting the histogram of the measurement of placental sonobyopsy at umbilical cord insertion ( $32^{\text {nd }}$ week of gestation). The sequence of the second histogram shows the exact value of the above-mentioned indices by VOCAL software.

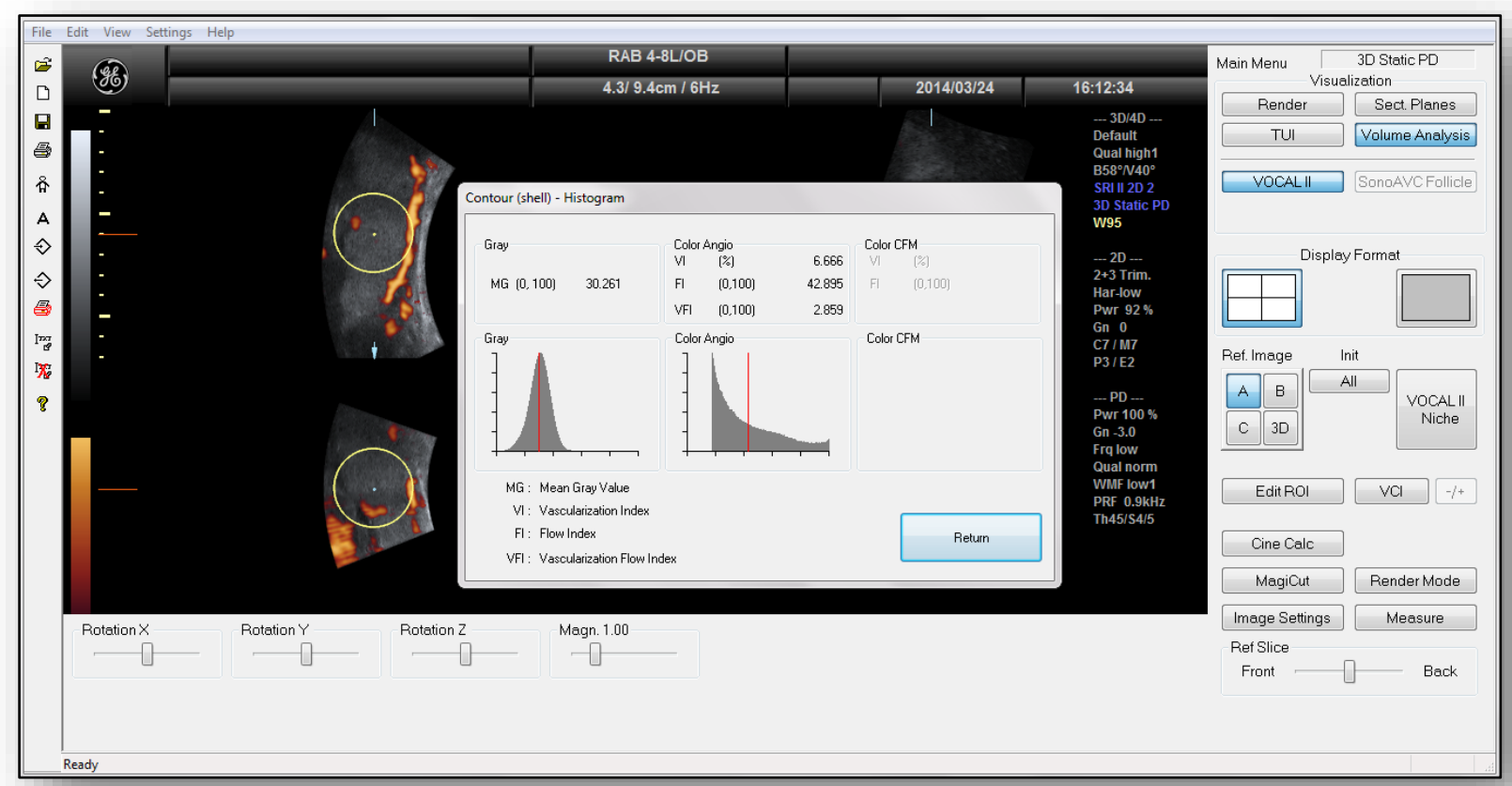




\subsection{Data collection}

\subsubsection{Maternal characteristics}

Data about mean maternal age, pregestational BMI, maternal obesity, and weight gain during pregnancy were collected. Data collected about gravity, parity, possible nicotine or cafe consumption and medication as well.

\subsubsection{Fetal characteristics}

Data about fetal biometry, placental attachment, amount of amniotic fluid, estimated fetal weight were collected.

\subsubsection{Neonatal characteristics}

Data about neonatal outcome and mode of delivery (normal delivery, planned cesarean section or acute cesarean section) were collected and classified after delivery. We collected data on 1-, 5-, and 10-minute Apgar scores, umbilical $\mathrm{pH}$, neonatal birth weight, rate of neonatal complications such as apnea, polycythemia, hypoglycemia, respiratory distress syndrome, dysmaturity and feeding difficulties, and the rate of macrosomia and premature birth.

\subsection{Histological analysis}

Histological analysis of placentae following delivery were performed. Histological preparations were made on the basis of the recommendation of The Royal College of Pathologists, UK. (86) We applied AxioVision SE64 Rel. 4.9.1. (Carl Zeiss Microscopy, LLC Thornwood, NY 10594, United States) software for assessing slides. 


\subsection{Statistical analyses}

Statistical analyses were conducted with IBM SPSS Statistics 21.0 for Windows program (IBM, New York, USA). Kolmogorov-Smirnov test results were significant for our database demonstrating that our study samples were not normally distributed. Continuous variables were expressed as median \pm standard deviation (SD). Kruskal-Wallis tests were used for comparison of continuous variables depending on the groups (CHT versus NBP; GHT versus NBP; PE versus NBP, CHT+GDM vs NBP, GHT+GDM vs NBP), whereas comparison between the pathological groups (CHT versus GHT; GHT versus PE, CHT vs CHT+GDM, GHT vs GHT+GDM) was assessed with Mann-Whitney U test in case of vascularization indices, and with Bartlett's test with Bonferroni's modification in case of AUtPSV, (level of significance was set at $\mathrm{P}<0,05)$. Univariate comparisons for categorical variables were assessed with $\chi 2$ tests. Linear regression coefficient values and equations depending on gestational age were also calculated for VI, FI, VFI and AUtPSV for all pathological and control groups. Association between placental 3-DPD indices, AUtPSV, maternal and fetal characteristics, two-dimensional color Doppler indices (PIs of umbilical and uterine arteries) were determined by Spearman's rank correlations and the multivariate relationship was analyzed using quantile regression. 


\section{Results}

Placental vascularization and AUtPSV values were investigated in $2^{\text {nd }}$ and $3^{\text {rd }}$ trimester, in an in-vivo study in case of pregnancy hypertension (CHT, GHT and PE), and pregnancy hypertension complicated with gestational diabetes mellitus (CHT+GDM and GHT+GDM).

\subsection{Placental vascularization indices}

\subsubsection{Vascularization index (VI)}

The analysis of 3D volume acquisition demonstrated that VI indices are significantly higher in CHT $(p=0.010)$ compared to NBP. In case of GHT, VI was lower $(p=0.152)$ compared to NBP, though the difference was not significant. There was significant difference between the CHT and GHT groups $(p=0.010)$ in case of VI as well.

In case of CHT+GDM $(p=0.010)$ and GHT+GDM $(p=0.010)$ we found significantly lower VI results compared to NBP. The analysis also demonstrated that there is significant difference between CHT and CHT+GDM $(p=0.010)$ in case of VI.

All PE cases evolved from GHT cases. The difference between GHT and PE groups in case of VI was not statistically significant $(p=0.175)$. See Table 8.

Table 8. Vascularization index (VI) in pregnancies with NBP, compared to CHT $(p=0.010)$, $\operatorname{CHT}+\operatorname{GDM}(p=0.010), \operatorname{GHT}(p=0.152), \operatorname{GHT}+\operatorname{GDM}(p=0.010)$, and PE.

\begin{tabular}{|l|c|c|c|c|c|c|}
\hline Parameter & $\begin{array}{c}\text { CHT+GDM } \\
(\mathrm{n}=15)\end{array}$ & $\begin{array}{c}\text { CHT } \\
(\mathrm{n}=43)\end{array}$ & $\begin{array}{c}\text { NBP } \\
(\mathrm{n}=109)\end{array}$ & $\begin{array}{c}\text { GHT } \\
(\mathrm{n}=57)\end{array}$ & $\begin{array}{c}\text { GHT+GDM } \\
(\mathrm{n}=23)\end{array}$ & $\begin{array}{c}\text { PE } \\
(\mathrm{n}=17)\end{array}$ \\
\hline VI $(\%, \operatorname{mean} \pm \mathrm{SD})$ & $5.3 \pm 3.5$ & $14.4 \pm 10.1$ & $10.4 \pm 6.2$ & $7.7 \pm 7.1$ & $5.4 \pm 2.4$ & $4.9 \pm 3.2$ \\
\hline
\end{tabular}

\subsubsection{Flow index $(\mathrm{FI})$}

In comparison with NBP group, FI was significantly lower in all pathological groups: CHT $(p=0.009)$, CHT+GDM $(p=0.010)$, GHT $(p<0.001)$, GHT+GDM $(p<0.001)$, and PE $(p<0.001)$ groups.

There was no statistically significant difference found between CHT and CHT+GDM $(p=0.354)$; GHT and GHT+GDM $(p=0.443)$; and GHT and PE $(p=0.183)$ groups. See Table 9. 
Table 9. Flow index (FI) in pregnancies with NBP, compared to CHT ( $p=0.009)$, CHT+GDM $(p=0.010)$, GHT $(p<0.001), \mathrm{GHT}+\mathrm{GDM}(p<0.001)$, and PE $(p<0.001)$.

\begin{tabular}{|l|c|c|c|c|c|c|}
\hline Parameter & $\begin{array}{c}\text { CHT+GDM } \\
(\mathrm{n}=15)\end{array}$ & $\begin{array}{c}\text { CHT } \\
(\mathrm{n}=43)\end{array}$ & $\begin{array}{c}\text { NBP } \\
(\mathrm{n}=109)\end{array}$ & $\begin{array}{c}\text { GHT } \\
(\mathrm{n}=57)\end{array}$ & $\begin{array}{c}\text { GHT+GDM } \\
(\mathrm{n}=23)\end{array}$ & $\begin{array}{c}\text { PE } \\
(\mathrm{n}=17)\end{array}$ \\
\hline FI $($ mean $\pm \mathrm{SD})$ & $42.8 \pm 9.6$ & $41.5 \pm 8.2$ & $46.1 \pm 7.6$ & $38.5 \pm 9.6$ & $36.4 \pm 8.3$ & $36.5 \pm 5.7$ \\
\hline
\end{tabular}

\subsubsection{Vascularization-flow index (VFI)}

For VFI, no significant difference was found between CHT and NBP $(p=0.973)$ and GHT and NBP $(p=0.075)$.

In case of VFI, no significant difference was found between CHT and CHT+GDM $(p=0.073), \mathrm{GHT}$ and GHT+GDM $(p=0.428)$ or PE $(p=0.128)$

Statistically significant difference can only be described when PE was compared to NBP $(p=0.010)$. See Table 10 .

Table 10. Vascularization-flow index (VFI) in pregnancies with NBP, compared to CHT $(p=0.973)$, CHT+GDM $(p=0.073)$, GHT $(p=0.075), \operatorname{GHT}+\operatorname{GDM}(p=0.428)$, and PE $(p=0.128)$.

\begin{tabular}{|l|c|c|c|c|c|c|}
\hline Parameter & $\begin{array}{c}\text { CHT+GDM } \\
(\mathrm{n}=15)\end{array}$ & $\begin{array}{c}\text { CHT } \\
(\mathrm{n}=43)\end{array}$ & $\begin{array}{c}\text { NBP } \\
(\mathrm{n}=109)\end{array}$ & $\begin{array}{c}\text { GHT } \\
(\mathrm{n}=57)\end{array}$ & $\begin{array}{c}\text { GHT+GDM } \\
(\mathrm{n}=23)\end{array}$ & $\begin{array}{c}\text { PE } \\
(\mathrm{n}=17)\end{array}$ \\
\hline VFI $(\operatorname{mean} \pm \mathrm{SD})$ & $2.3 \pm 1.5$ & $3.6 \pm 2.8$ & $4.1 \pm 2.5$ & $3.0 \pm 2.5$ & $2.0 \pm 1.1$ & $2.0 \pm 1.6$ \\
\hline
\end{tabular}

\subsection{Early diastolic notch}

Early diastolic notch results are presented in Table 11 below. The highest early diastolic notch rate was found in the PE group. The level of significance was found to be $p=0.012$ when the rate of early diastolic notch in PE was compared to GHT.

The rate was higher in CHT $(p=0.126)$ and in GHT $(p=0.004)$ as well compared to NBP. See Table 11.

Table 11. Early diastol $\mathrm{c}$ notch in pregnancies with NBP, CHT, GHT, and PE.

\begin{tabular}{|l|c|c|c|c|}
\hline Parameter & $\begin{array}{c}\text { CHT } \\
(\mathrm{n}=43)\end{array}$ & $\begin{array}{c}\text { NBP } \\
(\mathrm{n}=109)\end{array}$ & $\begin{array}{c}\text { GHT } \\
(\mathrm{n}=57)\end{array}$ & $\begin{array}{c}\text { PE } \\
(\mathrm{n}=17)\end{array}$ \\
\hline Early diastolic notch & $1 / 43(2.32 \%)$ & $0 / 109(0 \%)$ & $4 / 57(7.01 \%)$ & $6 / 17(36.29 \%)$ \\
\hline
\end{tabular}




\subsection{Uterine artery peak systolic velocity}

AUtPSV showed significant decrease in CHT $(p=0.012)$ compared to NBP, the difference between NBP and GHT was not statistically significant $(p=0.087)$.

There was significant increase between GHT+GDM and GHT $(p=0.048)$ groups, but there was no significant difference between CHT and CHT+GDM $(p=0.062)$, or GHT and PE $(p=0.320)$. See Table 12 .

Table 12. Uterine artery peak systolic velocity (AUtPSV) in pregnancies with NBP, CHT, CHT+GDM, GHT, GHT+GDM, and PE.

\begin{tabular}{|l|c|c|c|c|c|c|}
\hline Parameter & $\begin{array}{c}\text { CHT+GDM } \\
(\mathrm{n}=15)\end{array}$ & $\begin{array}{c}\text { CHT } \\
(\mathrm{n}=43)\end{array}$ & $\begin{array}{c}\text { NBP } \\
(\mathrm{n}=109)\end{array}$ & $\begin{array}{c}\text { GHT } \\
(\mathrm{n}=57)\end{array}$ & $\begin{array}{c}\text { GHT+GDM } \\
(\mathrm{n}=23)\end{array}$ & $\begin{array}{c}\text { PE } \\
(\mathrm{n}=17)\end{array}$ \\
\hline AUtPSV $(\mathrm{cm} / \mathrm{s}, \operatorname{mean} \pm \mathrm{SD})$ & $45.3 \pm 14.1$ & $50.0 \pm 16.6$ & $59.5 \pm 23.1$ & $56.8 \pm 18.4$ & $68.6 \pm 30.9$ & $52.4 \pm 13.0$ \\
\hline
\end{tabular}

\subsection{Maternal characteristics}

Maternal characteristics of pregnancies examined are presented in Table 13. below.

Table 13. Maternal characteristics in pregnancies with NBP, CHT, CHT+GDM, GHT, GHT+GDM, and PE.

\begin{tabular}{|l|c|c|c|c|c|c|}
\hline Table 13 & $\begin{array}{c}\text { CHT+GDM } \\
(\mathrm{N}=15)\end{array}$ & $\begin{array}{c}\text { CHT } \\
(\mathrm{N}=43)\end{array}$ & $\begin{array}{c}\text { NBP } \\
(\mathrm{N}=109)\end{array}$ & $\begin{array}{c}\text { GHT } \\
(\mathrm{N}=57)\end{array}$ & $\begin{array}{c}\text { GHT+GDM } \\
(\mathrm{N}=23)\end{array}$ & $\begin{array}{c}\text { PE } \\
(\mathrm{N}=17)\end{array}$ \\
\hline $\begin{array}{l}\text { Mean maternal age } \\
\text { (mean } \pm \text { SD) }\end{array}$ & $34.4 \pm 1.4$ & $32.8 \pm 4.2$ & $30.7 \pm 4.7$ & $31.1 \pm 5.4$ & $32.5 \pm 6.3$ & $29.5 \pm 5.2$ \\
\hline $\begin{array}{l}\text { Weeks of gestation } \\
\text { at the time of } 3 D \text { scan } \\
\text { (mean } \pm \text { SD) }\end{array}$ & $28^{+1} \pm 7^{+2}$ & $28^{+5} \pm 6^{+6}$ & $24^{+6} \pm 7^{+2}$ & $31^{+6} \pm 6^{+4}$ & $29^{+6} \pm 7^{+5}$ & $31^{+2} \pm 7^{+1}$ \\
\hline $\begin{array}{l}\text { Weeks of gestation } \\
\text { at the time of delivery } \\
\text { (mean } \pm \text { SD) }\end{array}$ & $37^{+4} \pm 1^{+5}$ & $38^{+5} \pm 1^{+1}$ & $38^{+3} \pm 1^{+6}$ & $38^{+0} \pm 2^{+2}$ & $37^{+1} \pm 2^{+3}$ & $36^{+6} \pm 3^{+5}$ \\
\hline
\end{tabular}

\subsubsection{Mean maternal age}

The highest mean maternal age was observed in the CHT+GDM group (NBP vs. CHT+GDM: $p=0.023)$. We also found increased mean maternal age in case of CHT and GHT+GDM $(p=0.037)$ compared to NBP. In case of GHT and PE there was no significant difference in mean maternal age compared to NBP. 


\subsubsection{Weeks of gestation at the time of $3 \mathrm{D}$ scan}

Figure 11. shows that pregnancies investigated are normally distributed through the second and third trimester.

Figure 11. Gestational age (GA) in weeks at the time of 3D scan in pregnancies with NBP, CHT, $\mathrm{CHT}+\mathrm{GDM}, \mathrm{GHT}, \mathrm{GHT}+\mathrm{GDM}$, and PE. $\left(\mathrm{N}=\mathrm{N} 2+\mathrm{N} 3: \mathrm{N} 2: 2^{\text {nd }}\right.$ trimester, N3: $3^{\text {rd }}$ trimester $)$

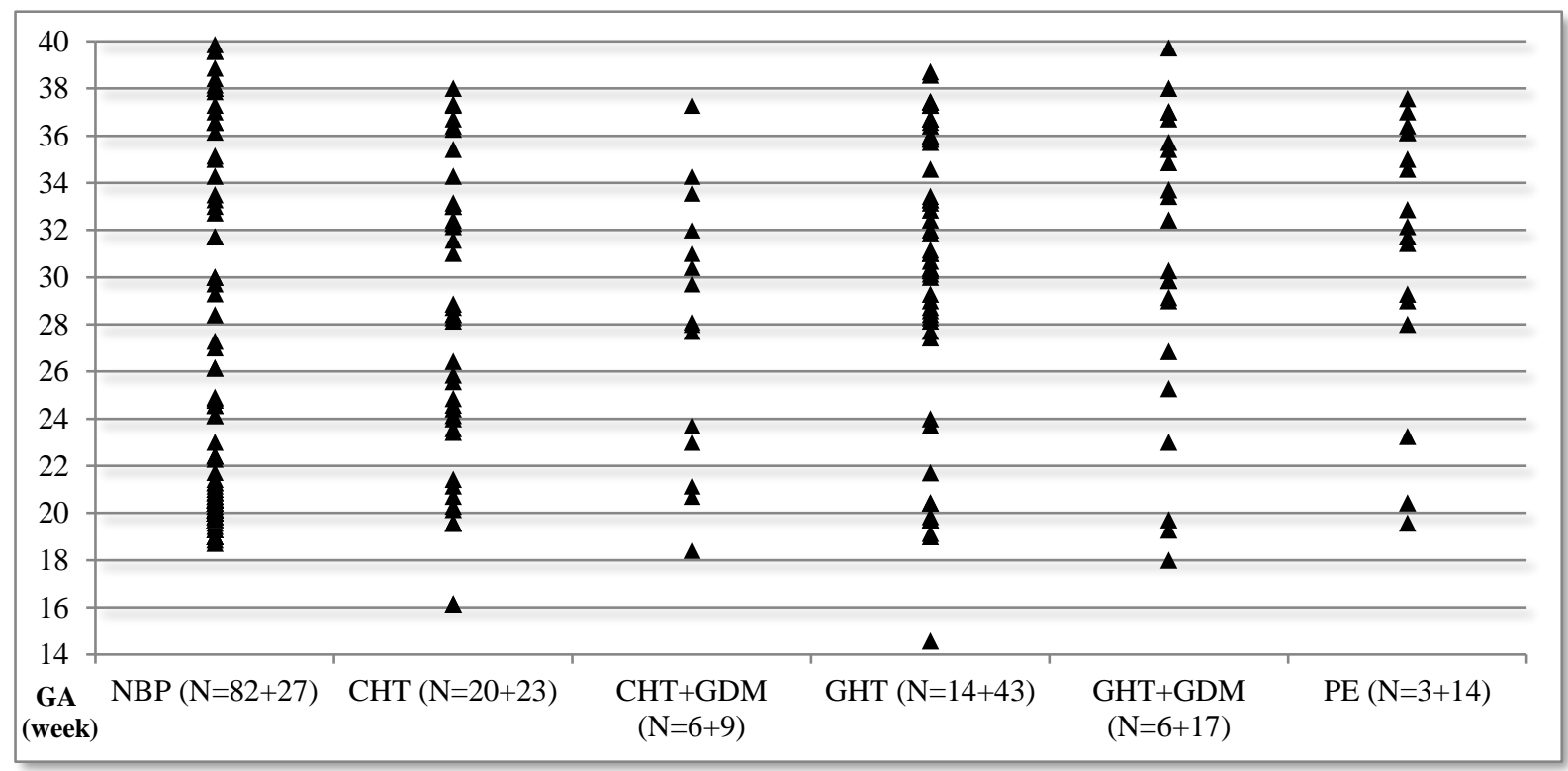

\subsubsection{Pre-gestational body mass index}

Pre-gestational BMI was significantly higher $(p<0.01)$ in GHT+GDM $(33.46 \pm 7.11)$ compared to GHT (30.37 \pm 5.80$)$, as well as in CHT+GDM (32.84 \pm 3.64$)$ compared to the CHT $(30.55 \pm 5.68)$ group.

Mean FI was 45.7 in case of normal pregestational BMI and 41.2 in case of elevated BMI. Elevated pregestational BMI had substantial influence on FI depression $(p=0.048)$.

\subsubsection{Maternal obesity and weight gain during pregnancy}

The highest maternal obesity rates were observed in the CHT (58.1\%), and the CHT+GDM (60.0\%) groups.

On the other hand, the highest levels of weight gain during pregnancy were observed in groups of pregnancies with GHT, with (GHT+GDM or PE) or without (GHT alone) additional pathologies. 


\subsubsection{Mode of delivery}

The lowest cesarean section rate was observed in the NBP group (26.6\%). In case of CHT $(67.4 \%)$ and GHT (64.9\%) the rate was markedly increased compared to NBP, but there was no significant difference between the two pathological groups.

When pregnancy hypertension was complicated with GDM the cesarean section rate was further increased: $\mathrm{CHT}+\mathrm{GDM}(80.0 \%)$, GHT+GDM (95.6\%). Interestingly the highest cesarean section rate was observed in the GHT+GDM group, even in the PE group the rate of normal delivery was three times higher than in GHT+GDM.

In the PE group, the rate of cesarean section (82.3\%) was higher than in the GHT group. See Figure 12.

Figure 12. Mode of delivery in pregnancies with NBP, CHT, CHT+GDM, GHT, GHT+GDM and PE.

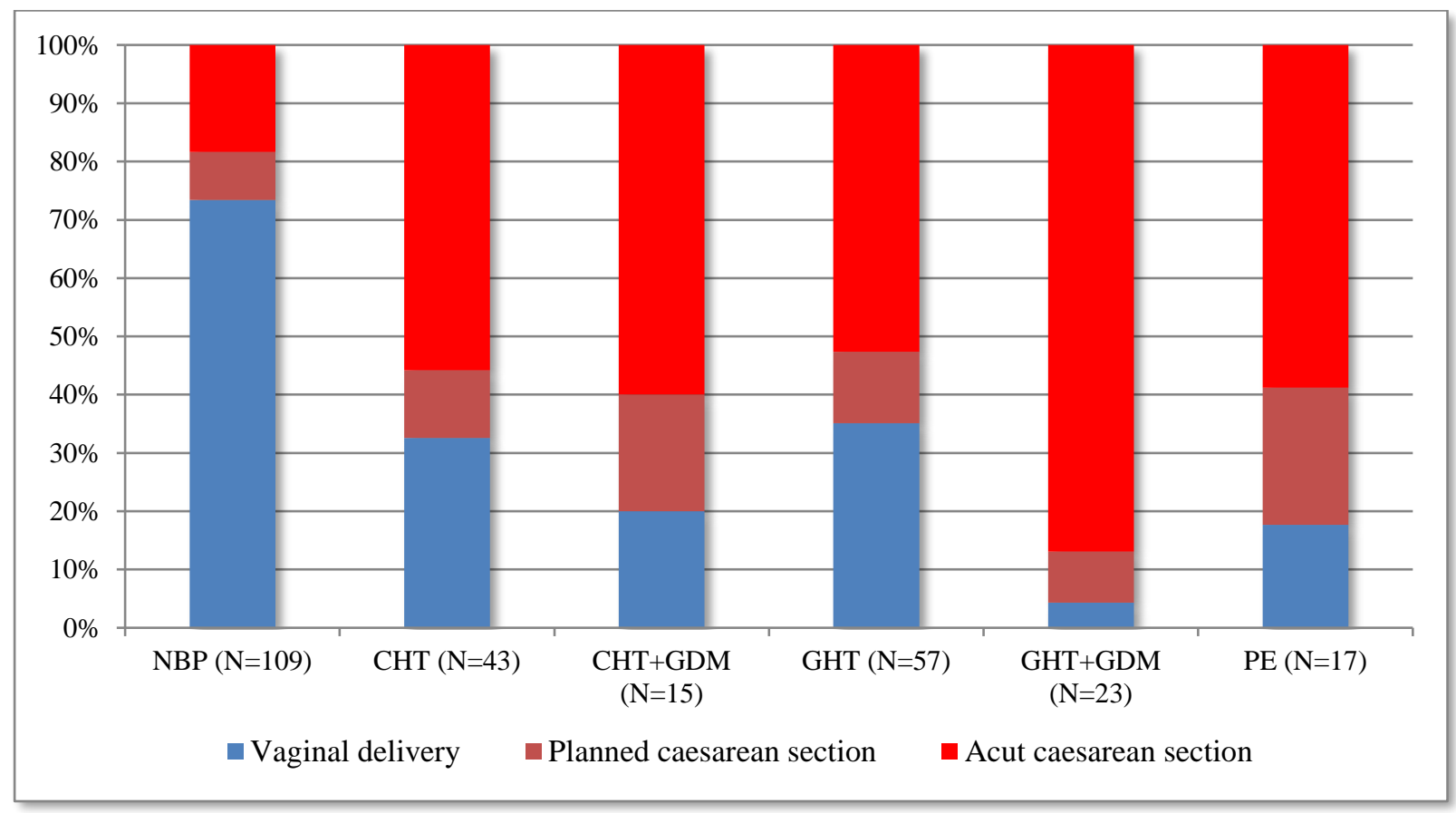




\subsection{Neonatal characteristics}

Neonatal characteristics of pregnancies investigated are presented in Table 14. below.

Table 14. Neonatal characteristics of pregnancies with NBP, CHT, CHT+GDM, GHT, GHT+GDM, and PE.

\begin{tabular}{|c|c|c|c|c|c|c|c|}
\hline \multicolumn{2}{|l|}{ Table 14} & $\begin{array}{c}\mathrm{CHT}+\mathrm{GDM} \\
(\mathrm{N}=15)\end{array}$ & $\begin{array}{c}\text { CHT } \\
(\mathrm{N}=43)\end{array}$ & $\begin{array}{c}\mathrm{NBP} \\
(\mathrm{N}=109)\end{array}$ & $\begin{array}{c}\text { GHT } \\
(\mathrm{N}=57)\end{array}$ & $\begin{array}{c}\text { GHT+GDM } \\
(\mathrm{N}=23)\end{array}$ & $\begin{array}{c}\mathrm{PE} \\
(\mathrm{N}=17)\end{array}$ \\
\hline \multirow{3}{*}{$\begin{array}{l}\text { Apgar score } \\
(\text { mean } \pm \text { SD) }\end{array}$} & $1^{\prime}$ & $8.30 \pm 0.75$ & $8.93 \pm 1.09$ & $8.86 \pm 0.57$ & $8.69 \pm 1.52$ & $8.21 \pm 1.75$ & $8.14 \pm 1.43$ \\
\hline & 5 & $9.53 \pm 0.66$ & $9.68 \pm 0.84$ & $9.50 \pm 0.67$ & $9.65 \pm 0.68$ & $9.39 \pm 1.15$ & $9.29 \pm 1.13$ \\
\hline & $10^{\prime}$ & $9.93 \pm 0.27$ & $9.91 \pm 0.35$ & $9.91 \pm 0.21$ & $9.82 \pm 0,60$ & $9.65 \pm 1.07$ & $9.55 \pm 0.84$ \\
\hline \multicolumn{2}{|l|}{$\begin{array}{l}\text { Umbilical pH } \\
(\text { mean } \pm \text { SD })\end{array}$} & $7.29 \pm 0.05$ & $7.23 \pm 0.07$ & $7.27 \pm 0.08$ & $7.26 \pm 0,07$ & $7.25 \pm 0.07$ & $7.25 \pm 0.07$ \\
\hline \multirow{6}{*}{$\begin{array}{l}\text { Perinatal } \\
\text { compli- } \\
\text { cations }\end{array}$} & Apnea & $7 / 15$ & $3 / 43$ & $9 / 109$ & $6 / 57$ & $5 / 23$ & $7 / 17$ \\
\hline & Polycythemia & $0 / 15$ & $2 / 43$ & $7 / 109$ & $7 / 57$ & $0 / 23$ & $2 / 17$ \\
\hline & $\begin{array}{l}\text { Hypogly- } \\
\text { cemia }\end{array}$ & $6 / 15$ & $1 / 43$ & $2 / 109$ & $2 / 57$ & $4 / 23$ & $3 / 16$ \\
\hline & RDS & $0 / 15$ & $0 / 43$ & $0 / 109$ & $0 / 57$ & $2 / 23$ & $3 / 16$ \\
\hline & Dysmaturity & $0 / 15$ & $0 / 43$ & $3 / 109$ & $4 / 57$ & $1 / 23$ & $12 / 17$ \\
\hline & $\begin{array}{l}\text { Feeding } \\
\text { difficulties }\end{array}$ & $6 / 15$ & $1 / 43$ & $7 / 109$ & $4 / 57$ & $5 / 23$ & $0 / 17$ \\
\hline \multicolumn{2}{|c|}{ Birth weight (grams) } & $3130 \pm 296$ & $3377 \pm 374$ & $3346 \pm 555$ & $3236 \pm 751$ & $3601 \pm 811$ & $2422 \pm 817$ \\
\hline
\end{tabular}

In the assessment of neonatal outcome rate of apnea, it was significantly higher in GHT patients $(p=0.042)$ compared to CHT patients and it was even more elevated in GHT+GDM $(p<0.001), \mathrm{CHT}+\mathrm{GDM}(p<0.001)$ and $\mathrm{PE}(p=0.001)$ cases.

One other characteristic perinatal complication specific to newborns of diabetic mothers, hypoglycemia was also significantly higher in CHT+GDM $(p=0.012)$ compared to CHT, and in GHT+GDM $(p=0.022)$ when compared to GHT.

Strong positive linear correlation was found between VI $(p=0.009)$, FI $(p=0.007)$ and neonatal birth weight (BW).

Premature birth rate was the highest in PE. All PE cases were consisted of patients with GHT and IUGR.

Male/female ratio was $32.5 \% / 67.5 \%$ in case of CHT, $47.7 \% / 52.3 \%$ in case of NBP, $54.3 \% / 45.7 \%$ in case of GHT, and $35.3 \% / 64.7 \%$ in case of PE. 


\subsection{Gravidity, parity and weight gain: influence on placental vascularization indices}

Since hypertension during pregnancy is determined by different maternal factors, we emphasized the influence of pregestational-BMI, primigravidity, and primiparity.

In case of elevated pregestational-BMI, FI decreased significantly in all three pathological groups.

Primiparity has a definite role in the development of GHT. Ratio of primiparity was $57.8 \%$ in GHT and only $37.2 \%$ in CHT. In our study $35 \%$ of pregnant women with GHT had one delivery before, and $7.2 \%$ of them had two or more deliveries. In the CHT group, the prevalence of two earlier pregnancies was $39.5 \%$ and the prevalence of three or more was $23.3 \%$.

We found that BMI and other maternal characteristics had no effect on placental vascularization indices in pregnancies either complicated by hypertensive disorder or not. See Table 15.

Table 15. Effects of maternal and fetal characteristics on placental vascularization indices in case of pregnancy hypertension (chronic-, gestational hypertension and preeclampsia cases examined as one)* - statistical methods used, and level of significance (N.S.: no significant difference, S.: significant difference was found).

\begin{tabular}{llllll}
\hline & $\begin{array}{c}\text { Statistical } \\
\text { method }\end{array}$ & VI & FI & VFI & p-value \\
\hline Gravidity & ANOVA & N.S. & N.S. & N.S. & $<0.001$ \\
\hline Parity & ANOVA & N.S. & N.S. & N.S. & $<0.001$ \\
\hline $\begin{array}{l}\text { Pregestational } \\
\text { BMI (normal) }\end{array}$ & ANOVA & N.S. & N.S. & N.S. & $<0.04$ \\
\hline $\begin{array}{l}\text { Pregestational } \\
\text { BMI (obese) }\end{array}$ & ANOVA & N.S. & N.S. & N.S. & $<0.04$ \\
\hline $\begin{array}{l}\text { Pregestational } \\
\text { BMI (excessive } \\
\text { weight gain)** }\end{array}$ & ANOVA & N.S. & N.S. & N.S. & $<0.04$ \\
\hline $\begin{array}{l}\text { Umbilical cord } \\
\text { arterial pH }\end{array}$ & Student's $t$ test & N.S. & S & N.S. & $<0.001$ \\
& & & & & \\
\hline
\end{tabular}




$\begin{array}{lccccc}\text { 1-minute } & \text { Mann-Whitney } & \text { N.S. } & \text { N.S. } & \text { N.S. } & <0.47 \\ \text { APGAR score } & \text { test } & & & \end{array}$

\begin{tabular}{lccccc}
\hline 5-minute & $\begin{array}{c}\text { Mann-Whitney } \\
\text { test }\end{array}$ & S. & S. & S. & $<0.04$ \\
APGAR score & Mann-Whitney & S. & S. & S. & $<0.046$ \\
10-minute & Student's t test & S. & S. & S. & $<0.01$ \\
\hline Birth Weight & Student's t test & S. & S. & S. & $<0.01$ \\
\hline $\begin{array}{l}\text { Estimated Foetal } \\
\text { Weight }\end{array}$ & & & & $<0.04$ \\
\hline $\begin{array}{l}\text { Placental } \\
\text { localisation }\end{array}$ & Student's t test & N.S & N.S. & N.S. & \\
\hline
\end{tabular}

* There was no significant difference between the pathological groups.

** Normal BMI before pregnancy with excessive weight gain during pregnancy.

\subsection{Histological findings}

The main histological characteristics of each pathological group are presented in Table 16 (18 cases of pregnancy hypertension: 5 CHT, 8 GHT and 5 PE). Vasculopathy was only seen in 2 out of 5 PE placentas, all PE cases were IUGR and two of them have been delivered preterm.

Table 16. Histological characteristics of placentas $(\mathrm{N}=18)$, in case of pregnancy hypertension (5 CHT,

8 GHT, 5 PE), that have been analyzed following delivery.

\begin{tabular}{|l|l|c|c|c|}
\hline $\begin{array}{l}\text { Histological characteristics of placentas with pregnancy } \\
\text { hypertension }\end{array}$ & $\begin{array}{l}\text { CHT } \\
\text { N=5 }\end{array}$ & GHT & PE \\
\hline Neutrophil invasion & & - & - & N=5 \\
\hline Interstitial fibrosis & No & 5 & 4 & - \\
& Mild & - & 4 & 3 \\
& Moderate & Severe & - & - \\
& Normovascularized & 3 & - & - \\
\hline Vascularization & Hypovascularized & 2 & - & - \\
\hline Parenchymal hematoma & & 2 & - & 5 \\
\hline Fibrin deposits & & 2 & 4 & 3 \\
\hline Syncytial knots & Yes & 2 & 3 & 5 \\
\hline & Moderate & 3 & 2 & - \\
\hline
\end{tabular}




\begin{tabular}{|l|l|c|c|c|}
\hline Calcification & None & 3 & - & - \\
& Peripheral & 1 & - & - \\
& Focal & 1 & 4 & - \\
\hline Chorioamnionitis & $-1-1$ & - & 5 \\
\hline Funisitis /the same patient that had chorioamnionitis/ & - & 1 & - \\
\hline Villitis & - & 1 & - \\
\hline Accelerated maturation & 1 & - & - & - \\
\hline
\end{tabular}

We found strong correlations between placental vascularization indices, and severity of pathohistological findings of placentas in case of pregnancy hypertension. See Figure 13a-f.

Figure 13. Histological characteristics of placentas in case of pregnancy hypertension (CHT, GHT and PE) based on the recommendation of the The Royal College of Pathologists. (86)

Figure 13a. Interstitial fibrosis - a histological characteristics of placentas in chronic hypertension (CHT), gestational hypertension (GHT) and preeclampsia (PE). Classification: no, mild, moderate, severe.

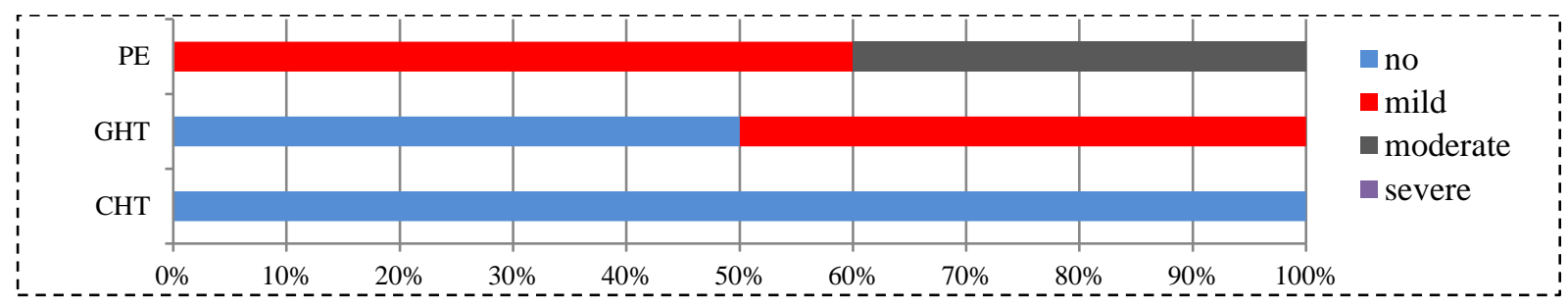

Figure 13b. Vascularization - a histological characteristics of placentas in chronic hypertension (CHT), gestational hypertension (GHT) and preeclampsia (PE). Classification: norm vascularized, hypovascularized.

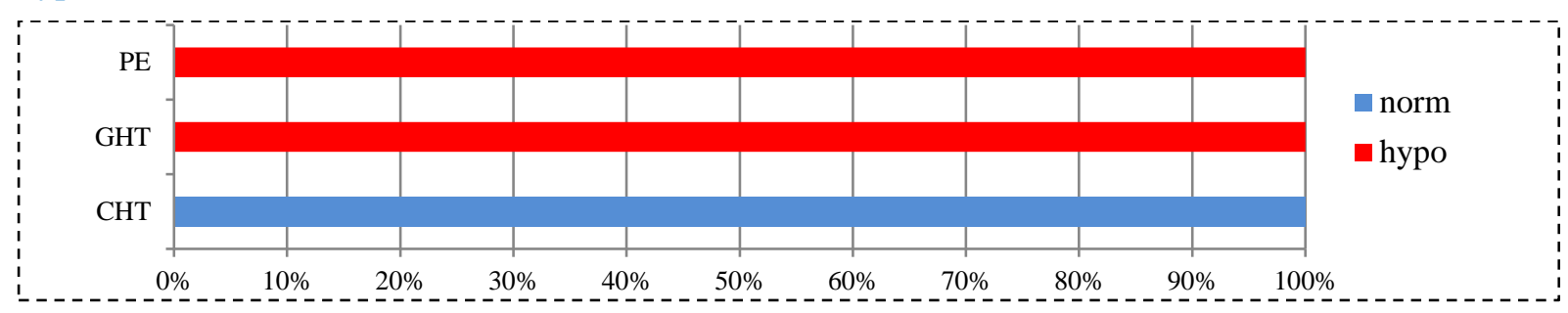

Figure 13c. Fibrin deposits - a histological characteristics of placentas in chronic hypertension (CHT), gestational hypertension (GHT) and preeclampsia (PE). Classification: no, yes.

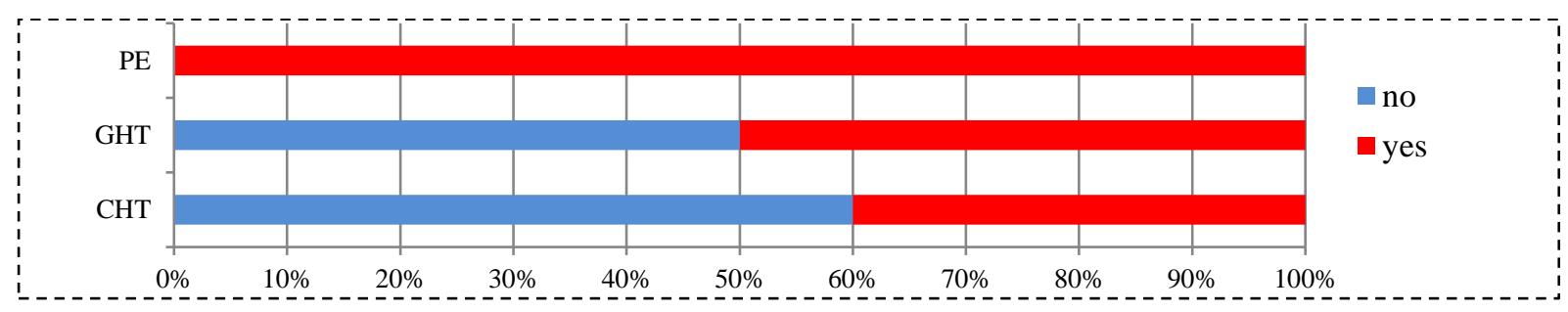


Figure 13d. Sycytial knots - a histological characteristics of placentas in chronic hypertension (CHT), gestational hypertension (GHT) and preeclampsia (PE). Classification: yes, moderate, severe.

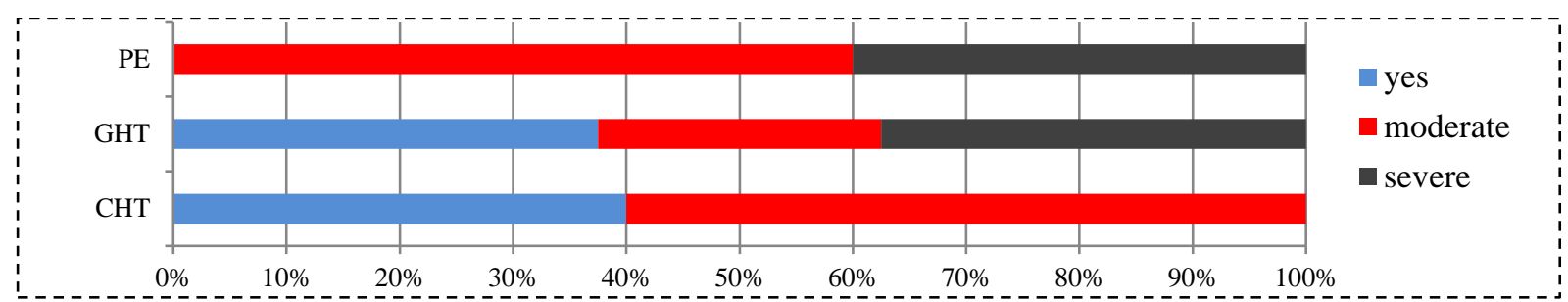

Figure 13e. Calcification - a histological characteristics of placentas in chronic hypertension (CHT), gestational hypertension (GHT) and preeclampsia (PE). Classification: none, peripheral, focal.

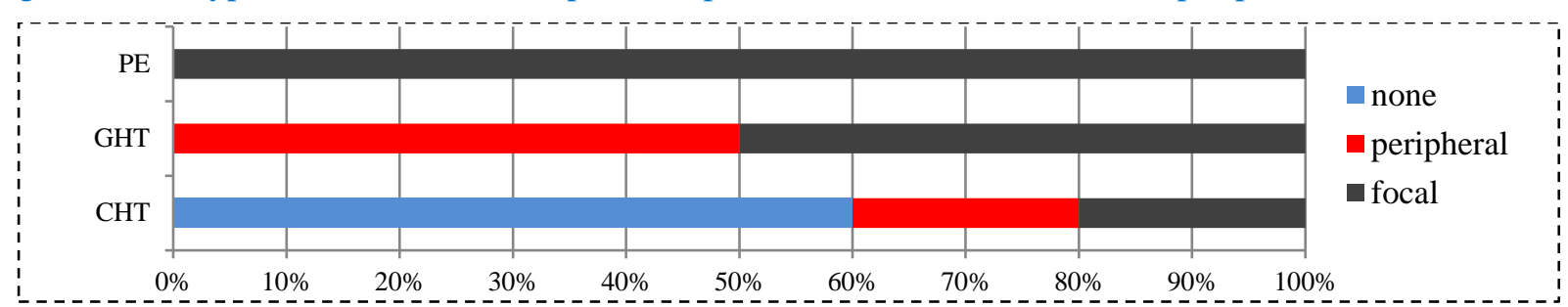

Figure 13f. Accelerated maturation - a histological characteristics of placentas in chronic hypertension (CHT), gestational hypertension (GHT) and preeclampsia (PE). Classification: no, yes.

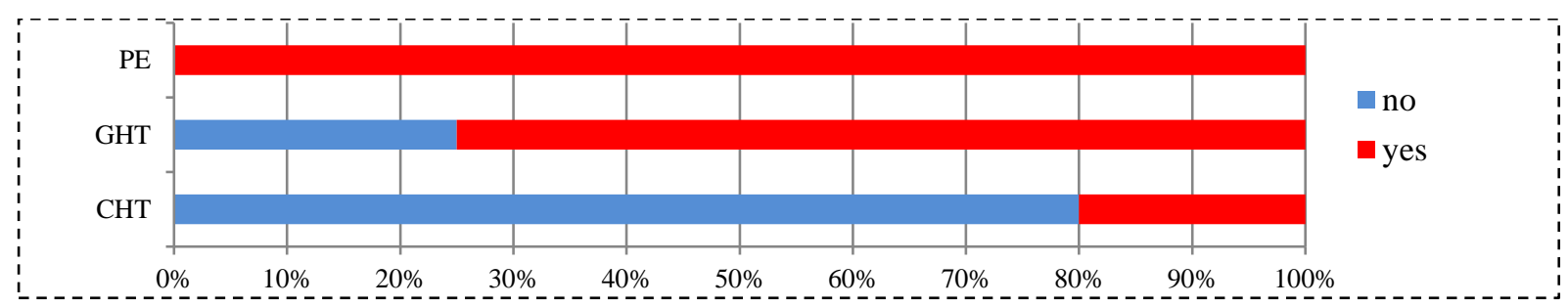

Figure 14. shows a normal blood pressure placenta, and Figure 15. shows a placenta from a pre-eclamptic patient. 
Figure 14. Histological preparation of normal blood pressure placenta. 40X Hematoxylin-eosin staining.
A: macroscopic image of a normal placenta.
B: macroscopic sectional image of the same placenta.
C: microscopic image of a norm vascularized placenta.

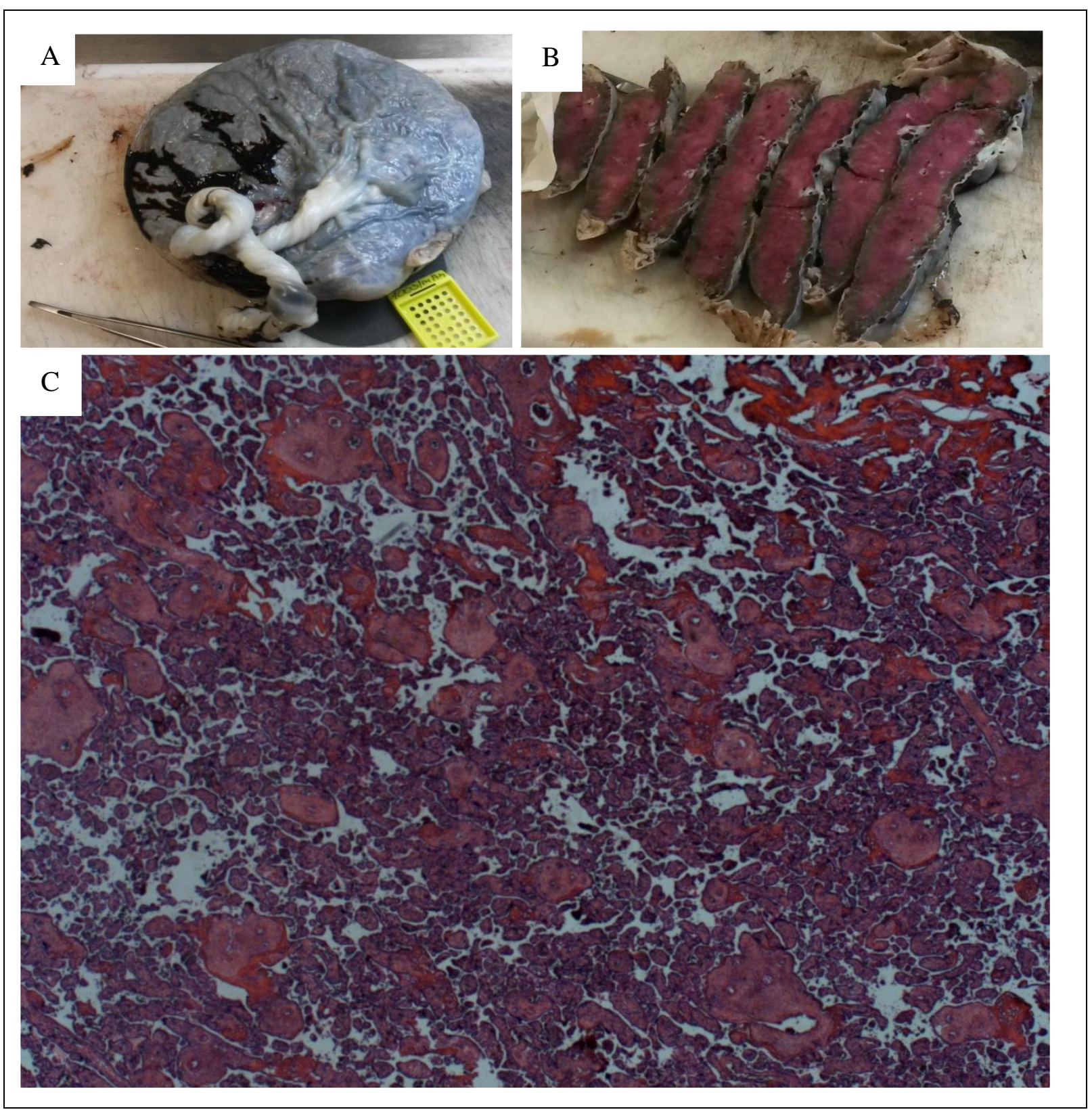


Figure 15. Histological preparation of preeclamptic placenta with intra uterine growth restriction. X 40 Hematoxylin-eosin staining.

A: macroscopic image of a preeclamptic placenta: it has smaller surface, more oblong in shape, and shows overall signs of under perfusion.

B: Cross sections of the eclamptic placenta showing multiple pale and infarcts.

C: microscopic image of a hypovascularized placenta, fibrin deposits, moderate interstitial fibrosis and syncytial knots, focal calcification and accelerated maturation are detectable.

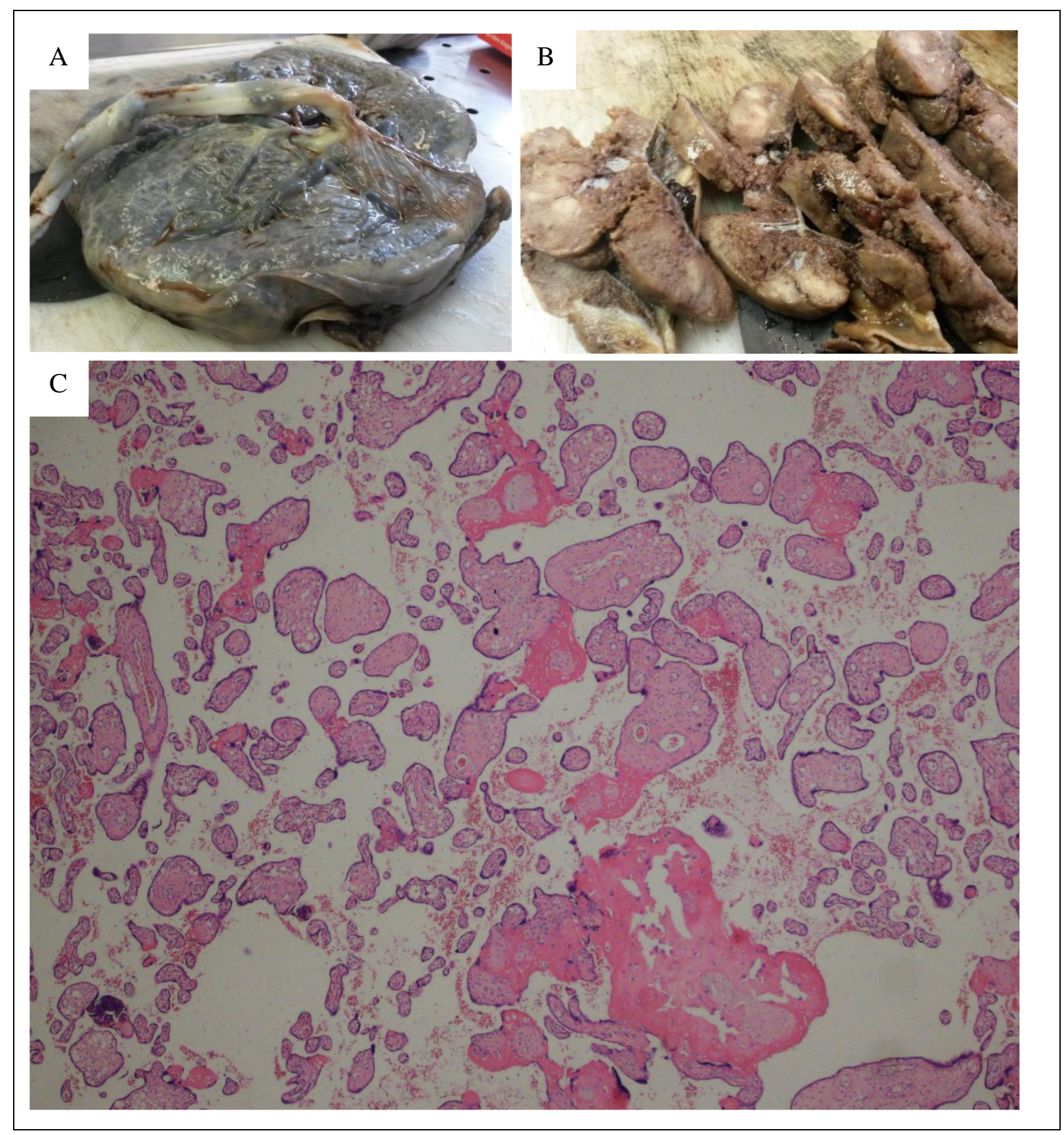




\section{Discussion}

Placental vascularization found lower in our $2^{\text {nd }}$ and $3^{\text {rd }}$ trimester in-vivo study in case of GHT and PE, and the effect of GDM on placental vascularization, and AUtPSV values in pregnancies complicated with pregnancy hypertension (CHT+GDM and GHT+GDM) were also determined.

While most publications reported only $1^{\text {st }}$ trimester data on placental vascularization indices, we examined placental vascularization, with the help of 3-DPD and VOCAL, in $2^{\text {nd }}$ and $3^{\text {rd }}$ trimester. We should also underline that, our study was the first, that examined the effect of GDM on placental vascularization indices and AUtPSV values in pregnancies complicated with pregnancy hypertension.

We found that placental vascularization indices in case of NBP were bio statistically constant during pregnancy. In pregnancies complicated by hypertensive disorders placental vascularization indices were decreased during pregnancy.

We also found that in $2^{\text {nd }}$ and $3^{\text {rd }}$ trimester, the placental vascularization is even more significantly lower in case of pregnancy hypertension compared to NBP cases despite ongoing antihypertensive treatment, than in $1^{\text {st }}$ trimester (87).

\subsection{Chronic hypertension}

In CHT cases involving predisposed pregnant women and normal placenta, maternal scavenging system will take part in pathological regulation of maternal blood pressure. This may lead to inadequate response of these systems, resulting in an overload and defect even if the vascular system of the placenta is normal.

In CHT we can say that, there is significantly lower FI rate, and significantly higher VI rate than in NBP, which clearly describes the nature of placental development in an unfriendly environment of pregnant women predisposed to chronic hypertension. This is a natural defense mechanism from the placenta against the unfriendly hemodynamic conditions.

Since the placenta has normal growth patterns in CHT, the development and malfunctions of maternal systems evolve more slowly than in GHT or PE. In our CHT cases placental growth was close to normal, which led to the development of milder clinical symptoms and perinatal complications than in GHT and especially in PE cases. Premature birth rate was almost 2.57 higher in GHT and 6.17 times higher in PE compared to CHT. 
AUtPSV in CHT was significantly lower compared to NBP, which may be the result of the higher VI rate, and it may also confirm the existence of a placental response on elevated maternal blood pressure predating pregnancy. Interestingly, GDM did not trigger the chronic hypoxic alteration in CHT group.

\subsection{Gestational hypertension}

In GHT cases comprising women with normal medical condition before pregnancy and dysfunctional placenta, the scavenging system of these pregnant women can cope with these deleterious changes in the placenta in the early period of gestation, then GHT and incidentally PE may develop.

Our results showed lower VI in pregnancies complicated by GHT and PE compared to NBP group, though the difference was not significant. Similarly, to Guiot et al. (88) and Odeh et al. (89), FI was statistically significantly lower in GHT and in PE groups compared to NBP group. We can highlight that GHT and PE cases have less placental blood perfusion than CHT or NBP, which is supported by lower VI and FI rates.

Clinical symptoms may only develop subsequently during pregnancy. Concurrently, maternal endothelium is affected only late in pregnancy and thus changes in placental vascularization are mostly related to PE (GHT complicated by IUGR) (5) rather than to CHT $(90,91)$. In this case, the fetus mostly develops into an abnormally grown baby. IUGR rate was $22.97 \%$ among GHT cases (17/74), which shows the progress rate to PE, although proteinuria and other dysfunction of maternal organs, such as renal insufficiency, liver dysfunction and neurological or hematological complications did not appear (5).

In GHT cases with IUGR no proteinuria could be detected probably because of antihypertensive therapy. It means that antihypertensive therapy may protects maternal renal function, but placental vascularization still can be destroyed.

There was no significant difference in AUtPSV between GHT, PE and NBP.

\subsection{Gestational diabetes mellitus}

The increased AUtPSV of diabetic women demonstrated in our study may reflect changes in systemic arteriolar placental afterload, myocardial contractility, heart rate and preload. The placenta in diabetic pregnancy has morphological changes that may result in reduced uteroplacental perfusion. The absence of a difference in uterine artery PI values between 
fetuses of diabetic women and normal controls argues against a modification increased arterial compliance may increase AUtPSV without altering afterload (92).

AUtPSV was significantly higher in GHT+GDM compared to both CHT and GHT, which correlates with the higher adverse pregnancy outcome rates specific to GDM.

The highest mean maternal age was found in case of pregnancy hypertension complicated with GDM, highlighting the fact that higher maternal age is an important risk factor in GDM. Above it the GDM has effect on neonatal outcome, as well. GDM gives a higher rate for hypoglycemic episodes and feeding difficulties.

Macrosomia is most likely to occur in case of gestational diabetes. The lower macrosomia rate on the other hand in case of GHT+GDM compared to NBP or CHT+GDM might be the result of impaired placentation in case of GHT that prevented GHT+GDM cases end up with macrosomia in neonates.

\subsection{Adverse pregnancy outcome}

The fetal characteristic features of hypoxia were not elevated in CHT and GHT patients compared to NBP patients. Occurrence of apnea was about 4 times higher, while hypoglycemia was about 5 times higher in PE compared to all other groups.

Since hypertension during pregnancy is determined by different maternal factors, we emphasized the influence of pregestational-BMI and primigravidity/primiparity. In case of elevated pregestational-BMI, FI decreased significantly in CHT, GHT and PE groups. Primiparity has a definite role in the development of GHT. Primiparity ratio was $57.8 \%$ in GHT and $37.2 \%$ in CHT. Furthermore, in second or third pregnancies the chance of CHT rises. In our study, GHT was 35\% for the second gestation, $7.2 \%$ for the third or higher number gestations. In the CHT group, the prevalence of two earlier pregnancies was $39.5 \%$ and the prevalence of three or more was $23.3 \%$

\subsection{Limitations}

There are some limitations to our study. The method is very sensitive and, therefore, we had to reduce the interobserver bias:

1. We had to apply standardized settings of the ultrasound equipment.

2. The same person had to perform all the ultrasound examinations, and collect clinical data. 
3. The same person had to analyze the 3-DPD volume files without the awareness of the clinical data.

4. As fetal movements and maternal respiratory movements result in artifacts in the 3DPD records we had to ask the mother to lay as motionless as possible.

Data recording and analyzing are time consuming, thus these kinds of investigations are difficult to introduce into routine maternal care. 


\section{Conclusion}

Our goal was to examine placental vascularization in $2^{\text {nd }}$ and $3^{\text {rd }}$ trimester, on etiological basis. We found that certain placental vascularization indices and AUtPSV may indicate on significant differences due to gestational pathology, thus placental vascularization indices and AUtPSV can be useful in the early detection of pregnancies at risk in order to possibly prevent complications.

From my point of view the measurement of placental vascularization indices is a useful tool in risk prediction, differential diagnosis, and determining anti-hypertensive therapy effectivity, while uterine artery peak systolic velocity helps to find pregnant women at risk for gestational diabetes mellitus earlier. 


\section{New statements}

1. There is significant difference in 3-DPD placental vascularization indices, between case group of pregnancy hypertension and control group of normal blood pressure pregnancies.

2. There is significant difference in 3-DPD placental vascularization indices, between pathological groups of chronic-, gestational hypertension and preeclampsia.

3. There is negative correlation between placental 3-DPD vascularization indices and the severity of pregnancy hypertension case.

4. There are significant differences in 3-DPD placental vascularization indices and maternal characteristics among pregnancy hypertension types (CHT, GHT and PE).

5. There are significant differences in 3-DPD placental vascularization indices and fetal characteristics among pregnancy hypertension types (CHT, GHT and PE).

6. There are significant differences in 3-DPD placental vascularization indices and neonatal characteristics among pregnancy hypertension types (CHT, GHT and PE).

7. There is negative correlation between placental 3-DPD vascularization indices and adverse pregnancy outcome rates.

8. The value of uterine artery peak systolic velocity (AUtPSV) is increased in case of pregnancy hypertension when complicated with gestational diabetes mellitus.

9. There is negative correlation between placental 3-DPD indices and the severity of histological finding of the placenta in case of pregnancy hypertension.

10. The measurement of placental 3-DPD vascularization indices with the help of VOCAL software in second and third trimester, in case of pregnancy hypertension (CHT, GHT and $\mathrm{PE}$ ) can be a useful screening method in the prevention of complications.

11. The measurement of uterine artery peak systolic velocity (AUtPSV) can be a useful method of screening gestational diabetes mellitus (GDM). 


\section{Acknowledgement}

I would like to express my foremost and deepest gratitude to my supervisors, Andrea Surányi MD, PhD, Med Habil, and Prof. Gábor Németh MD, PhD, Med Habil, present head of Department of Obstetrics and Gynecology, University of Szeged, providing me with this fantastic research topic, that is very popular and flourish nowadays and supporting me through the hardest days of research. I thank for their devoted and tireless supervisor activity and for helping me to perform the practical and theoretical part of my study. I can never be grateful enough to their kind assistance in preparation of the abstracts, posters, manuscripts and my Ph.D. dissertation.

I have learnt from them that continuous scientific activity, and insight gives the ability to improve myself consecutively, and that serves my patients the best

I would like to thank to Prof. Attila Pál MD, the former head of Department of Obstetrics and Gynecology, University of Szeged, for his kind support. I thank him that he gave me the opportunity to join his team, and to gave me the best supervisors no one can ever imagine!

I express my sincere gratitude to Prof. György Bártfai MD, DSc, Director of Reproductive Health Programme for his support. Special thanks to Tibor Nyári, PhD, Habil, for his help in statistical analyses. I also thank to László Kaiser M.D. and Mária Jakó MD for their help in histological preparations, and analyses.

I would like to say thank to my colleges at the Department of Obstetrics and Gynecology, University of Szeged for their help in patient recruitment.

I would like to thank to Prof. Zoltán Tóth MD head of Hungarian Society of Ultrasound in Obstetrics and Gynaecology (MSZNUT) for his financial support in presenting my work on international congresses.

I would like to thank to Sándor Vári MD and Cedars Sinai Medical Center's International Research and Innovation in Medicine Program, the Association for Regional Cooperation in the Fields of Health, Science and Technology (RECOOP HST Association) for their support of my work as participating Cedars - Sinai Medical Center - RECOOP Research Centers (CRRC). I would also like to thank to Srećko Gajović, MD, PhD former editor-in-chief of Croatian Medical Journal for his support in publishing my work, and to the International Society for the Study of Hypertension in Pregnancy (ISSHP) for their Travel Award in 2015.

I am extremely grateful to every member of my family especially to Zsuzsanna, my fiancée, who served me with a steady and quiet background. 


\section{Literature}

(1) Taylor RN, Roberts JM, Cunningham FG, et al. Chesley's Hypertensive Disorders in Pregnancy. ISBN: 978-0-12-407866-6 Elsevier 2015;Ch1:1-24.

(2) American College of Obstetricians and Gynecologists. Hypertension in Pregnancy. 2013;Ch1:14. ISBN: 978-1-934984-28-4. https://www.acog.org/Resources-AndPublications/Task-Force-and-Work-Group-Reports/Hypertension-in-Pregnancy (updated 2013/ accessed 01.09.2017.)

(3) Royal College of Obstetricians and Gynecologists. Hypertension in pregnancy: diagnosis and management. NICE 2010.Ch1.2.3.1. https://www.nice.org.uk/ guidance/cg107/chapter/1-Guidance\#management-of-pregnancy-with-chronichypertension (updated 01.2011./ accessed 01.09.2017.)

(4) Magee LA, Pels A, Helewa $M$ et al. SOGC CLINICAL PRACTICE GUIDELINE. Diagnosis, Evaluation, and Management of the Hypertensive Disorders of Pregnancy: Executive Summary. J Obstet Gynaecol Can. 2014 ;36:416-41.

(5) Tranquilli AL, Dekker G, Magee L, et al. The classification, diagnosis and management of the hypertensive disorders of pregnancy: a revised statement from the ISSHP. Pregnancy Hypertens. 2014;4:97-104.

(6) Taylor RN, Roberts JM, Cunningham FG, et al. Chesley's Hypertensive Disorders in Pregnancy. ISBN: 978-0-12-407866-6 Elsevier 2015;Ch14:291-313.

(7) Capeless EL, Clapp JF. Cardiovascular changes in early phase of pregnancy. Am J Obstet Gynecol. 1989;161:1449-53.

(8) Robson SC, Hunter S, Boys RJ, et al. Serial study of factors influencing changes in cardiac output during human pregnancy. Am J Physiol. 1989;256:1060-5.

(9) Taylor RN, Roberts JM, Cunningham FG, et al. Chesley's Hypertensive Disorders in Pregnancy. ISBN: 978-0-12-407866-6 Elsevier 2015; Ch15:315-334

(10) Monos E, Berczi V, Nadasy G. Local control of veins: Biomechanical, metabolic, and humoral aspects. Physiol Rev. 1995;75:611-66.

(11) Cha SC, Aberdeen GW, Nuwayhid BS, et al. Influence of pregnancy on mean systemic filling pressure and the cardiac function curve in guinea pigs. Can J Physiol Pharmacol. 1992;70:669-74.

(12) Hohman M, Keve TM, Osol G, et al. Norepinephrine sensitivity of mesenteric veins in pregnant rats. Am J Physiol. 1990;259:753-59. 
(13) Shroff SG. Pulsatile arterial load and cardiovascular function - acts, fiction, and wishful thinking. Therapeutic Res. 1998;19:59-66.

(14) Poppas A, Shroff SG, Korcarz CE et al. Serial assessment of the cardiovascular system in normal pregnancy: role of arterial compliance and pulsatile arterial load. Circulation. 1997;95:2407-15.

(15) Simmons LA, Gillin AG, Jeremy RW. Structural and functional changes in left ventricle during normotensive and preeclamptic pregnancy. Am J Physiol Heart Circ Physiol. 2002;283:1627-33.

(16) Hibbard JU, Korcarz CE, Nendaz-Giardet G, et al. Arterial system in preeclampsia and chronic hypertension with superimposed preeclampsia. Brit J Obstet Gynecol. 2005;112:897-903.

(17) Lang RM, Pridjian G, Feldman T, et al. Left ventricular mechanics in preeclampsia. Am Heat J. 1991;121:1768-75.

(18) Dechend R, Viedt C, Muller DN. AT1 receptor agonistic antibodies from preeclamptic patients stimulate NADPH oxidase. Circulation. 2003;107:1632-39.

(19) Zhou CC, Ahmad S, Mi T. Autoantibody from women with preeclampsia induces soluble fms-like tyrosine kinase 1 production via angiotensin type 1 receptor and calcineurin nuclear factor of activated T-cells signaling. Hypertension. 2008;51:101019.

(20) Taylor RN, Roberts JM, Cunningham FG, et al. Chesley's Hypertensive Disorders in Pregnancy. ISBN: 978-0-12-407866-6 Elsevier 2015; Ch17:379-96.

(21) Hayashi M, Inoute T, Hoshimoto K, et al. Characterization of five marker levels of the hemostatic system and endothelial status in normotensive pregnancy and preeclampsia. Eur J Haematol. 2002;69:297-302.

(22) Ballegeer VC, Spitz B, De Baene LA, et al. Platelet activation and vascular damage in gestational hypertension. Am J Ostet Gynecol. 1992;166:629-33.

(23) Moffett A, Loke C. Immunology of placentation in eutherian mammals. Nature Reviews Immunology 6, 2006:584-94.

(24) Robertson WB, Brosens I, Dixon HG. The pathological response of the vessels of the placental bed to hypertensive pregnancy. J Pathol Bacteriol. 1967;93:581-92.

(25) Brosens IA, Robertson WB, Dixon HG. The role of spiral arteries in the pathogenesis of preeclampsia. Obstet Gynecol Annu.1972;1:177-91.

(26) Redline RW: Contemporaly Ob/Gyn: Placental pathology: Is it time to get serious? 2014. Modern Medicine Network online: http://contemporaryobgyn.modernmedicine. 
com/contemporary-obgyn/content/tags/maternal-fetal-medicine/placental-pathology-ittime-get-serious?page=full (updated 01.02.2014./ accessed 01.09.2017.)

(27) Jerzy S. Hypoxic Patterns of Placental Injury: A Review. Archives of Pathology \& Laboratory Medicine. 2013;137:706-20.

(28) Folkman J, Merler E, Abernathy C, et al. Isolation of a tumor factor responsible for angiogenesis. The Journal of Experimental Medicine. 1971;133:275-88.

(29) Senger DR, Galli SJ, Dvorak AM, et al. Tumor cells secrete a vascular permeability factor that promotes accumulation of ascites. Science. 1983;219:983-5.

(30) Plouët J, Schilling J, Gospodarowicz D. Isolation and characterization of a newly identified endothelial cell mitogen produced by AtT-20 cells. The EMBO Journal. 1989;8:3801-6.

(31) Kukk E, Lymboussaki A, Taira S, et al. VEGF-C receptor binding and pattern of expression with VEGFR-3 suggests a role in lymphatic vascular development. Development. 1996;122:3829-37.

(32) Plate KH, Breier G, Weich HA, et al. Vascular endothelial growth factor is a potential tumor angiogenesis factor in human gliomas in vivo. Nature. 1992;359:845-8.

(33) Maglione D, Guerriero V, Viglietto G, et al. Isolation of a human placenta cDNA coding for a protein related to the vascular permeability factor. Proceedings of the National Academy of Sciences of the United States of America. 1991;88:9267-71.

(34) Maynard SE, Min JY, Merchan J, et al. Excess placental soluble fms-like tyrosine kinase 1 (sFlt1) may contribute to endothelial dysfunction, hypertension, and proteinuria in preeclampsia. J Clin Invest. 2003;111:649-58.

(35) Ahmad S, Ahmed A. Elevated placental soluble vascular endothelial growth factor receptor-1 inhibits angiogenesis in preeclampsia. Circ Res. 2004;95:884-91.

(36) Gullai N, Stenczer B, Molvarec A, et al. Evaluation of a rapid and simple placental growth factor test in hypertensive disorders of pregnancy. Hypertens Res. 2013;36:45762.

(37) Robinson CJ, Johnson DD, Chang EY, et al. Evaluation of placenta growth factor and soluble Fms-like tyrosine kinase 1 receptor levels in mild and severe preeclampsia. Am J Obstet Gynecol. 2006;195:255-9.

(38) Chaiworapongsa T, Romero R, Espinoza J, et al. Evidence supporting a role for blockade of the vascular endothelial growth factor system in the pathophysiology of preeclampsia. Am J Obstet Gynecol. 2004;190:1541-7. 
(39) Karumanchi SA, Epstein FH. Placental ischemia and soluble fms-like tyrosine kinase 1: cause or consequence of preeclampsia? Kidney Int. 2007;71:959-61.

(40) Gilbert JS, Babcock SA, Granger JP. Hypertension produced by reduced uterine perfusion in pregnant rats is associated with increased soluble fms-like tyrosine kinase-1 expression. Hypertension. 2007;50:1142-7.

(41) Lu F, Longo M, Tamayo E, et al. The effect of over-expression of sFlt-1 on blood pressure and the occurrence of other manifestations of preeclampsia in unrestrained conscious pregnant mice. Am J Obstet Gynecol. 2007;196:396.e1-7.

(42) Verlohren S, Herraiz I, Lapaire O, et al. The sFlt-1/PlGF ratio in different types of hypertensive pregnancy disorders and its prognostic potential in preeclamptic patients, Am J Obstet Gynecol. 2012;206:58.e1-8.

(43) Zeisler H, Llurba E, Chantraine F, et al. Predictive value of the sFlt-1:PlGF ratio in women with suspected preeclampsia, N Engl J Med. 2016;376:13-22.

(44) Gallo D, Poon LC, Fernandez M, et al. Prediction of preeclampsia by mean arterial pressure at 11-13 and 20-24 weeks' gestation. Fetal Diagn Ther. 2014;36:28-37.

(45) Wright D, Syngelaki A, Akolekar R, et al. Competing risks model in screening for preeclampsia by maternal characteristics and medical history. Am J Obstet Gynecol. 2015;213:62.e1-10.

(46) Gallo DM, Wright D, Casanova C, et al. Competing risks model in screening for preeclampsia by maternal factors and biomarkers at 19-24 weeks' gestation. Am J Obstet Gynecol. 2016;214:619.e1-17.

(47) Tsiakkas A, Saiid Y, Wright A, et al. Competing risks model in screening for preeclampsia by maternal factors and biomarkers at 30-34 weeks' gestation. Am J Obstet Gynecol. 2016;215:87.e1-17.

(48) Andrietti S, Silva M, Wright A, et al. Competing-risks model in screening for preeclampsia by maternal factors and biomarkers at 35-37 weeks' gestation. Ultrasound Obstet Gynecol. 2016;48:72-9.

(49) Dragan I, Wright D, Fiolna M, et al. Development of pre-eclampsia within 4 weeks of sFlt-1/P1GF ratio > 38: comparison of performance at 31-34 vs 35-37 weeks' gestation. Ultrasound Obstet Gynecol. 2017;49:209-12.

(50) Conde-Agudelo A, Althabeb F, J. M. Belizán, et al. Cigarette smoking during pregnancy and risk of preeclampsia: a systematic review. Am J Obstet Gynecol. $1999 ; 181: 1026-35$. 
(51) Jeyabalan A, Powers RW, Durica AR, et al. Cigarette Smoke Exposure and Angiogenic Factors in Pregnancy and Preeclampsia. Am J Hypertens. 2008;21:943-7.

(52) Kun A, Tornoczky J, Tabak AG. Prevalence and predictors of GDM in Hungary. Horm Metab Res. 2011;43:788-93.

(53) Ehrenberg HM, Mercer BM, Catalano PM. The influence of obesity and diabetes on the prevalence of macrosomia. Am J Obstet Gynecol. 2004;191:964-8.

(54) Sheffield JS, Butler-Koster EL, Casey BM, et al. Maternal diabetes mellitus and infant malformations. Obstet Gynecol. 2002;100:925-30.

(55) Horvath K, Koch K, Jeitler K, et al. Effects of treatment in women with gestational diabetes mellitus: systematic review and meta-analysis. BMJ 2010;340:c1395.

(56) Expert Committee on the diagnosis and classification of diabetes mellitus: Report of the Expert Committee in the diagnosis and classification of diabetes mellitus. Diabetes Care. 2011;34(Suppl.1):S66-8.

(57) Hiden U, Froehlich J, Desoye G. Diabetes and the Placenta. In: Kay HH, Nelson DM, Wang Y editors. The Placenta: From Development to Disease. 1st ed. UK: Oxford. WileyBlackwell; 2011:228-30.

(58) Vambergue A, Valat A, Dufour P et al. Pathophysiology of gestational diabetes. J Gynecol Obstet Biol Reprod (Paris). 2002;31:4S3-10.

(59) Brian AM, Philip O, James D. Clinical obstetrics and gynecology. 2nd ed. Saunders Elsevier; 2009.Ch30:266-289.

(60) Desoye G, Hauguel de Mouzon S. The Human Placenta in Gestational Diabetes Mellitus. Diabetes Care. 2007;30(Supplement 2): S120-6.

(61) de Onis M, Garza C, Onyango AW, et al. WHO growth standards for infants and young children. Arc Pediatr. 2009;16:47-53.

(62) Lausman A, McCarthy FP, Walker M, et al. Screening, diagnosis and management of IUGR. J Obstet Gynecol Can. 2012; 34:17-28.

(63) Romo A, Carceller R, Tobajas J. Intrauterine growth retardation (IUGR): epidemiology and etiology. Pediatr Endocrinol Rev. 2009;6:332-6.

(64) Surányi A. Prenatal and postnatal evaluation of fetal renal hyperechogenicity in pregnancies complicated with pre-eclampsia and intrauterine growth retardation (Ph.D. thesis). University of Szeged. 2000:16.

(65) Suhag A, Berghella V. Intrauterine Growth Restriction (IUGR): Etiology and Diagnosis Curr Obstet Gynecol Rep. 2013;2:102-11. 
(66) Charnock-Jones DS, Kaufmann P, Mayhew TM. Aspects of human fetoplacental vasculogenesis and angiogenesis. I. Molecular regulation. Placenta. 2004;25(2-3):10313.

(67) Rigó J, Asztalos M. A terhesség alatti hypertonia ellátásának diagnosztikus és terápiás irányelvei [Pregnancy hypertension: diagnostic and therapeutic guidelines]. In: Papp Z. Szülészeti-nőgyógyászati protokoll [Obstetrical and gynecological guideline]; 2002.Ch7:259-265.

(68) Coustan DR, Lowe LP, Metzger BE et al. The HAPO Study: Paving The Way For New Diagnostic Criteria For GDM. Am J Obstet Gynecol. 2010;202:654.e1-6.

(69) Gilmartin AH, Ural SH, Repke JT. Gestational diabetes mellitus. Rev Obstet Gynecol. 2008;1:129-34.

(70) Riccabona M, Nelson TR, Pretorius DH. Three-dimensional ultrasound: accuracy of distance and volume measurements. Ultrasound Obstet. Gynecol. 1996;7:429-34.

(71) Neto RM, Ramos JG. 3D power Doppler ultrasound in early diagnosis of preeclampsia. Preg Hypertens. 2015;1:10-6.

(72) Odibo AO, Goetzinger KR, Huster KM, et al. Placental volume and vascular flow assessed by $3 \mathrm{D}$ power Doppler and adverse pregnancy outcomes. Placenta. 2011;32:230-4.

(73) Merce LT, Barco MJ, Bau S, et al. Assessment of placental 362 vascularization by three-dimensional power Doppler "vascular biopsy" in normal 363 pregnancies. Croat Med J. 2005;46:765-71.

(74) Hafner E, Philipp T, Schuchter K, et al. Second-trimester measurements of placental volume by three-dimensional ultrasound to predict small-for gestational age infants. Ultrasound Obstet Gynecol. 1998;12:97-102.

(75) Tuuli MG, Houser M, Odibo L, et al. Validation of placental vascular sonobiopsy for obtaining representative placental vascular indices by three-dimensional power Doppler ultrasonography. Placenta. 2010;31:192-6.

(76) Hadlock FP, Harrist RB, Sharman RS, et al. Estimation of fetal weight with the use of head, body, and femur measurements-a prospective study. Am J Obstet Gynecol. $1985 ; 151: 333-7$.

(77) Nicolaides K, Rizzo G, Hecker K, et al. Methodology of Doppler assessment of the placental and fetal circulations: uteroplacental circulation. In: ISUOG. Doppler in obstetrics. London: Fetal Medicine Foundation. 2002:32-61. 
(78) Bower S, Bewley S, Campbell S. Improved prediction of pre-eclampsia by two-stage screening of uterine arteries using the early diastolic notch and color Doppler imaging. Obstet Gynecol. 1993;82: 78-83

(79) Nicolaides K, Rizzo G, Hecker K, et al. Doppler in Obstetrics 2002,Ch5 https://sonoworld.com/client/fetus/html/doppler/capitulos-html/chapter_05.htm (updated 2002/accessed 01.09.2017)

(80) Thompson RS, Trudinger BJ, Cook CM. Doppler ultrasound waveform indices: A/B ratio, pulsatility index and Pourcelot ratio. Br J Obstet Gynecol. 1988;95:581-8.

(81) Surányi A, Kozinszky Z, Molnár A, et al. Placental three-dimensional power Doppler indices in mid-pregnancy and late pregnancy complicated by gestational diabetes mellitus. Prenat Diagn. 2013;33:952-8.

(82) Rubin JM, Bude RO, Carson PL, et al. Power Doppler US: a potentially useful alternative to mean frequency-based color Doppler US. Radiology. 1994;190:853-6.

(83) Maulik D. Sonographic color flow mapping: Basic principles, in: Maulik D. (Ed.), Doppler Ultrasound in Obstetrics and Gyneology, Spring-Verlag Inc, New York, 1997:69-84.

(84) Pretorius DH, Nelson TR, Baergen RN, et al. Imaging of placental vasculature using three-dimensional ultrasound and color power Doppler: a preliminary study, Ultrasound Obstet. Gynecol. 1998;12:45-9.

(85) Rizzo G, Capponi A, Pietrolucci ME, et al. First trimester placental volume and three dimensional power doppler ultrasonography in type I diabetic pregnancies. Prenat Diagn. 2012;32:480-4.

(86) Phillip C, Clair E. Tissue pathway for histopathological examination of the placenta, in: The Royal College of Pathologists Guideline, 2011. https://www.rcpath.org/resourceLibrary/tissue-pathway-placenta_sept11.html (updated 26.09.2011/ accessed 01.09.2017.)

(87) de Almeida Pimenta EJ, Silva de Paula CF, Duarte Bonini Campos JA, et al. Threedimensional sonographic assessment of placental volume and vascularization in pregnancies complicated by hypertensive disorders, J. Ultrasound Med. 2014;33:48391.

(88) Guiot C, Gaglioti P, Oberto M, et al. Is three-dimensional power Doppler ultrasound useful in the assessment of placental perfusion in normal and growth-restricted pregnancies? Ultrasound Obstet Gynecol. 2008;31:171-6. 
(89) Odeh M, Ophir E, Maximovsky O, et al. Placental volume and three-dimensional power Doppler analysis in prediction of pre-eclampsia and small for gestational age between 11 and 13 weeks and 6 days of gestation. Prenat Diagn. 2011;31:367-71.

(90) Pilalis A, Souka AP, Antsaklis P, et al. A screening for pre-eclampsia and small for gestational age fetuses at the 11-14 weeks scan by uterine artery Dopplers. Acta Obstet Gynecol Scand. 2007;86:530-4.

(91) Savvidou MD, Yu CK, Harland LC, et al. Maternal serum concentration of soluble fms-like tyrosine kinase 1 and vascular endothelial growth factor in women with abnormal uterine artery Doppler and in those with fetal growth restriction. Am J Obstet Gynecol. 2006;195:1668-73.

(92) Ursem NT, Clark EB, Keller BB, et al. Fetal heart rate and umbilical artery velocity variability in pregnancies complicated by insulin-dependent diabetes mellitus. Ultrasound Obstet Gynecol. 1999;13:312-6. 
13. Annex I.-II. 